NBER WORKING PAPER SERIES

\title{
JOINT-SEARCH THEORY: NEW OPPORTUNITIES AND NEW FRICTIONS
}

\author{
Bulent Guler \\ Fatih Guvenen \\ Giovanni L. Violante \\ Working Paper 15011 \\ http://www.nber.org/papers/w15011
NATIONAL BUREAU OF ECONOMIC RESEARCH
1050 Massachusetts Avenue
Cambridge, MA 02138

May 2009

The authors thank seminar and conference participants at various research institutions for helpful comments. Guvenen thanks the National Science Foundation for financial support under grant no SES-0649437. All remaining errors are our own. The views expressed herein are those of the author(s) and do not necessarily reflect the views of the National Bureau of Economic Research.

NBER working papers are circulated for discussion and comment purposes. They have not been peerreviewed or been subject to the review by the NBER Board of Directors that accompanies official NBER publications.

(C) 2009 by Bulent Guler, Fatih Guvenen, and Giovanni L. Violante. All rights reserved. Short sections of text, not to exceed two paragraphs, may be quoted without explicit permission provided that full credit, including $\odot$ notice, is given to the source. 
Joint-Search Theory: New Opportunities and New Frictions

Bulent Guler, Fatih Guvenen, and Giovanni L. Violante

NBER Working Paper No. 15011

May 2009

JEL No. E24,J61,J64

\begin{abstract}
$\underline{\text { ABSTRACT }}$
Search theory routinely assumes that decisions about the acceptance/rejection of job offers (and, hence, about labor market movements between jobs or across employment states) are made by individuals acting in isolation. In reality, the vast majority of workers are somewhat tied to their partners--in couples and families--and decisions are made jointly. This paper studies, from a theoretical viewpoint, the joint job-search and location problem of a household formed by a couple (e.g., husband and wife) who perfectly pools income. The objective of the exercise, very much in the spirit of standard search theory, is to characterize the reservation wage behavior of the couple and compare it to the single-agent search model in order to understand the ramifications of partnerships for individual labor market outcomes and wage dynamics. We focus on two main cases. First, when couples are risk averse and pool income, joint search yields new opportunities--similar to on-the-job search--relative to the single-agent search. Second, when the two spouses in a couple face job offers from multiple locations and a cost of living apart, joint-search features new frictions and can lead to significantly worse outcomes than single-agent search.
\end{abstract}

Bulent Guler

University of Texas at Austin

Austin, TX

bguler@gmail.com

Fatih Guvenen

Department of Economics

University of Minnesota

4-151 Hanson Hall

1925 Fourth Street South

Minneapolis, MN, 55455

and NBER

guvenen@umn.edu
Giovanni L. Violante

Department of Economics

New York University

19 W. 4th Street

New York, NY 10012-1119

and NBER

glv2@nyu.edu 


\section{Introduction}

In the year 2000 , over $60 \%$ of the US population was married, the labor force participation rate of married women stood at $61 \%$, and in one-third of married couples wives provided more than $40 \%$ of household income (US Census (2000); Raley, Mattingly, and Bianchi (2006)). For these households, which make up a substantial fraction of the population, economic decisions are jointly taken by the two spouses. Among such decisions, job search, broadly defined, is arguably one of the most crucial to the economic well-being of a household.

Macroeconomics is rapidly shifting away from the stylized "bachelor model" of the household by explicitly recognizing the relevance of household-level decisions for aggregate economic outcomes. ${ }^{1}$ Surprisingly, instead, since its inception in the early 1970s, search theory has almost entirely focused on the single-agent search problem. The recent survey by Rogerson, Shimer, and Wright (2005), for example, does not contain any discussion on optimal job search strategies of two-person households acting as the decision units. This state of affairs is rather surprising given that Burdett and Mortensen (1977), in their seminal piece entitled "Labor Supply Under Uncertainty," lay out a two-person search model and sketch a characterization of its solution, explicitly encouraging further work on the topic. Their pioneering effort, which remained virtually unfollowed, represents the starting point of our theoretical analysis.

In this paper, we study the job search problem of a couple who faces exactly the same economic environment as in the standard single-agent search problem of McCall (1970) and Mortensen (1970) without on-the-job search, and Burdett (1978) with on-the-job search. A couple is an economic unit composed of two identical individuals linked to each other by the assumption of perfect income pooling. The simple unitary model of a household adopted here is a convenient and logical starting point. It helps us to examine more transparently the role of the labor market frictions and insurance opportunities introduced by joint-search, and it makes the comparison with the canonical singleagent search model especially stark.

From a theoretical perspective, couples would make a joint decision leading to choices different from those of a single agent for several reasons. We start from the two most natural and relevant ones. First, the couple has concave preferences over pooled income. Second, the couple can receive job offers from multiple locations, but faces a utility cost of living apart. In this latter, case deviations from the single-agent search problem occur even for linear preferences. As summarized by the title of our paper, in the first environment joint search introduces new opportunities, whereas in the second it introduces new frictions relative to single-agent search. One appealing feature of our theoretical analysis is that it leads to two-dimensional diagrams in the space of the two spouses' wages $\left(w_{1}, w_{2}\right)$, where the reservation wage policies can be easily analyzed and interpreted.

In the first environment we study, couples have risk-averse preferences and have access to a

\footnotetext{
${ }^{1}$ For example, see Aiyagari et al. (2000) on intergenerational mobility and investment in children, Cubeddu and Rios-Rull (2003) on precautionary saving, Blundell et al. (2007) on labor supply, Heathcote et al. (2008) and Lise and Seitz (2008) on economic inequality, and Guner et al. (2009) on taxation.
} 
risk-free asset for saving but are not allowed to borrow. A dual-searcher couple (both members unemployed) will quickly accept a job offer - in fact, more easily than a single unemployed agent. However, the worker-searcher couple (one spouse unemployed, the other employed) will be more choosy in accepting the second job offer. The dual-searcher couple can use income pooling to its advantage: it initially accepts a lower wage offer (to smooth consumption across states) while, at the same time, not giving up completely the search option (to increase lifetime income) that remains available to the other spouse. We formally show that the gap between the reservation wage of the worker-searcher couple (a function of the employed spouse's wage) and that of the dual-searcher couple (a constant) depends on the degree of absolute risk aversion in preferences, and on how absolute risk aversion changes with the level of consumption.

Furthermore, if the second spouse receives and accepts a very good job offer, this may trigger a quit by the employed spouse to search for a better job, resulting in a switch between the breadwinner and the searcher within the household. As is well known, this endogenous quit behavior never happens in the standard single-agent version of the search model. We call this process - of quitsearch-work that allows a couple to climb the wage ladder even in absence of on-the-job search - the "breadwinner cycle." Therefore, one can view joint search as a "costly" version of on-the-job search, even in the formal absence of it. The cost comes from the fact that in order to keep the search option active, the pair must remain a worker-searcher couple, and must not enjoy the full wage earnings of a dual-worker couple as it would be capable of doing in the presence of on-the-job search. Overall, relative to singles, couples spend more time searching for better jobs, which results in longer unemployment durations, but it eventually leads to higher lifetime wages and welfare.

We uncover two "equivalence results" between single-agent search and joint-search outcomes. The first environment requires the presence of on-the-job search, with equal search effectiveness on and off the job. The second requires the presence of loose borrowing limits. In both cases, a risk-averse couple acts like a single agent. These equivalence results follow directly from the value added of joint search in terms of climbing the wage ladder and of smoothing consumption, as discussed above. Finally, we also show an intuitive and useful result: the joint-search model is exactly isomorphic to a model where a single agent searches for jobs, and she has the possibility of holding multiple jobs.

Our second model features two locations and a flow cost of living apart for the two spouses in the couple. The couple has to choose reservation functions with respect to "inside offers" (jobs in the current location) and "outside offers" (jobs in the other location). Even with risk-neutral preferences, the search behavior of couples differs from that of single agents in important ways. First, the dual-searcher couple is less choosy than the individual agent because it is effectively facing a worse job offer distribution, since some wage offer configurations are attainable only in different locations - hence, by paying the cost of living apart. Second, there is a region in which the breadwinner cycle is optimal for the couple. For example, a couple who keeps getting better and better offers from the outside location could be better off if the currently employed spouse quits and follows the spouse with the highest offer to the new location. It should be noted that we also 
obtained these two results in our previous environment, but for completely different reasons.

The model allows us to formalize what Mincer (1978) called tied-stayers - i.e., workers who turn down a job offer in a different location that they would accept as single - and tied-movers-i.e., workers who accept a job offer in the location of the partner that they would turn down as single. Overall, the disutility of living separately effectively narrows down the job offers that are viable for couples, who end up choosing among a more limited set of job options. We show, through simulations, that for plausible parameter values, joint search yields outcomes that are significantly different from single-agent search. For example, when the disutility cost (of living separately) is equal to $15 \%$ of a dual-worker couples' average wage earnings, more than half of all moving households involve a partner who is a tied-mover, and the lifetime income of each spouse in a couple is $6.5 \%$ lower than comparable singles.

The set of propositions proved in the paper formalizes the new opportunities and the new frictions in terms of comparison between the reservation wage functions of the couple and the reservation wage of the single agent. We also provide some illustrative simulations to show that the deviations of joint-search behavior from its single-agent counterpart can be quantitatively substantial.

Only very recently, a handful of papers have started to follow the lead offered by Burdett and Mortensen (1977) into the investigation of household interactions in frictional labor market models. Garcia-Perez and Rendon (2004) numerically simulate a model of family-based job-search decisions to tease out the importance of the added worker effect for consumption smoothing. Dey and Flinn (2008) study quantitatively the effects of health insurance coverage on employment dynamics in a search model where the economic unit is the household. Gemici (2008) estimates a rich structural model of migration and labor market decisions of couples to assess the implications of joint location constraints on labor outcomes and the marital stability of couples. Relative to these contributions, our paper is less ambitious in its quantitative analysis, but it provides a more focused and systematic study of joint-search theory.

From a theoretical perspective, our analysis of the one-location model has useful points of contacts with existing results in search theory applied to at least three separate contexts. First, starting from the static analysis of Danforth (1979), a number of papers have studied the role of risk-free wealth in shaping dynamic job-search decisions (e.g., Browning et al., 2003; Pissarides, 2004; Lentz and Tranaes, 2005). The income of the spouse differs crucially from risk-free wealth because it is risky (in the presence of exogenous separations), and because it can be optimally controlled by the job-search decision itself. Second, Albrecht and Vroman (2009) study a different type of joint-search decision, that of a committee that votes on an option which gives some value to each member. The authors are interested in drawing a comparison between single-agent search and committee search, in the same spirit as our exercise. ${ }^{2}$ Third, as we explain in the main text, there is an analogy with

\footnotetext{
${ }^{2}$ The similarities, though, stop here more or less. For example, Albrecht and Vroman (2009) also find that committees are less picky than single agents. In our one-location model, this result is due to a consumption-smoothing argument. In their environment, it is due to the negative externality that committee members impose on each other (e.g., voting against when drawing a particularly low value).
} 
some search models of marriage formation where the flow value of the marriage is a concave function of the sum of the spouses' endowments (e.g., Visschers, 2006).

The rest of the paper is organized as follows. Section 2 describes the single-agent problem which provides the benchmark of comparison throughout the paper. Section 3 develops and fully characterizes the baseline joint-search problem. Section 4 extends this baseline model in a number of directions: nonparticipation, on-the-job search, exogenous separations, and access to borrowing. Section 5 studies an economy with multiple locations and a cost of living apart for the couple. Section 6 concludes the paper and discusses how to relax some of the stark assumptions we made. The Appendix contains detailed proofs of all our propositions.

\section{The Single-Agent Search Problem}

We begin by first presenting the sequential job-search problem of a single agent - the well-known McCall-Mortensen model (McCall, 1970; Mortensen, 1970). This model provides a useful benchmark against which we compare the joint-search model, which we introduce in the next section. For clarity of exposition, we begin with a very stylized version of this optimal stopping problem, and then consider several extensions in Section 4.

Economic environment. Consider an economy populated with individuals who all participate in the labor force: agents are either employed or unemployed. Time is continuous and there is no aggregate uncertainty. Workers maximize the expected lifetime utility from consumption,

$$
E_{0} \int_{0}^{\infty} e^{-r t} u(c(t)) d t
$$

where $r$ is the subjective rate of time preference, $c(t)$ is the instantaneous consumption flow at time $t$, and $u(\cdot)$ is the instantaneous utility function.

An unemployed worker is entitled to an instantaneous benefit, $b$, and receives wage offers, $w$, at rate $\alpha$ from an exogenous wage offer distribution, $F(w)$ with support $[0, \infty)$. The worker observes the wage offer, $w$, and decides whether to accept or reject it. If he accepts the offer, he becomes employed at wage $w$ forever. If he rejects the offer, he continues to be unemployed and to receive job offers. All individuals are identical in terms of their labor market prospects, i.e., they face the same wage offer distribution and the same arrival rate of offers, $\alpha$. There are no exogenous separations and no on-the-job search. Finally, we assume that individuals have access to risk-free saving but are not allowed to borrow. As will become clear below, in the present framework individuals face a wage earnings profile that is nondecreasing over the life cycle (without exogenous separation risk), and, therefore, consumption smoothing only requires the ability to borrow but does not benefit from the ability to save. As a result, individuals will optimally set consumption equal to their wage earnings every period even though they are allowed to save. ${ }^{3}$

\footnotetext{
${ }^{3}$ Borrowing, on-the-job search, exogenous job separation, and nonparticipation are introduced in Section 4.
} 
Value functions. Denote by $V$ and $W$ the value functions of an unemployed and employed agent, respectively. Then, using the continuous time Bellman equations, the problem of a single worker can be written in the following flow value representation: ${ }^{4}$

$$
\begin{aligned}
r V & =u(b)+\alpha \int \max \{W(w)-V, 0\} d F(w), \\
r W(w) & =u(w) .
\end{aligned}
$$

This well-known problem yields a unique reservation wage, $w^{*}$, for the unemployed such that for any wage offer above $w^{*}$, she accepts the offer and below $w^{*}$, she rejects the offer. Furthermore, this reservation wage can be obtained as the solution to the following equation:

$$
\begin{aligned}
u\left(w^{*}\right) & =u(b)+\frac{\alpha}{r} \int_{w^{*}}\left[u(w)-u\left(w^{*}\right)\right] d F(w) \\
& =u(b)+\frac{\alpha}{r} \int_{w^{*}} u^{\prime}(w)[1-F(w)] d w
\end{aligned}
$$

which equates the instantaneous utility of accepting a job offer paying the reservation wage (lefthand side, LHS) to the option flow value of continuing to search in the hope of obtaining a better offer in the future (right-hand side, RHS). Since the LHS is increasing in $w^{*}$, whereas the RHS is a decreasing function of $w^{*}$, equation (3) uniquely determines the reservation wage, $w^{*}$.

\section{The Joint-Search Problem}

We now study the search problem of a couple facing the same economic environment described above. For the purposes of this paper, a "couple" is defined as an economic unit composed of two individuals who are ex ante identical in their preferences and the labor market parameters they face. The two individuals perfectly pool income to purchase a market good which is jointly consumed by the couple.

As before, because households are not able to borrow and saving is not optimal, they simply consume their total income in each period, which is the sum of the wage or benefit income of each spouse. Couples make their job acceptance/rejection/quit decisions jointly, because each spouse's search behavior affects the couple's joint welfare.

A couple can be in one of three labor market states. First, if both spouses are unemployed and searching, they are referred to as a "dual-searcher couple." Second, if both spouses are employed (an absorbing state), we refer to them as a "dual-worker couple." Finally, if one spouse is employed and the other is unemployed, we refer to them as a "worker-searcher couple." As can perhaps be anticipated, the most interesting state is the last one.

\footnotetext{
${ }^{4}$ Below, when the limits of integration are not explicitly specified, they are understood to be the lower and upper bound of the support of $w$.
} 
Value functions. Let $U$ denote the value function of a dual-searcher couple, $\Omega\left(w_{1}\right)$ the value function of a worker-searcher couple when the worker's wage is $w_{1}$, and $T\left(w_{1}, w_{2}\right)$ the value function of a dual-worker couple earning wages $w_{1}$ and $w_{2}$. The flow value in the three states becomes

$$
\begin{aligned}
r T\left(w_{1}, w_{2}\right) & =u\left(w_{1}+w_{2}\right), \\
r U & =u(2 b)+2 \alpha \int \max \{\Omega(w)-U, 0\} d F(w), \\
r \Omega\left(w_{1}\right) & =u\left(w_{1}+b\right)+\alpha \int \max \left\{T\left(w_{1}, w_{2}\right)-\Omega\left(w_{1}\right), \Omega\left(w_{2}\right)-\Omega\left(w_{1}\right), 0\right\} d F\left(w_{2}\right) .
\end{aligned}
$$

The equations determining the first two value functions (4) and (5) are straightforward analogs of their counterparts in the single-search problem. In the first case, both spouses stay employed forever, and the flow value is simply equal to the total instantaneous wage earnings of the household. In the second case, the flow value is equal to the instantaneous utility of consumption (which equals the total unemployment benefit) plus the expected gain in case a wage offer is received. Because both agents receive wage offers at rate $\alpha$, the total offer arrival rate of a dual-searcher couple is $2 \alpha .^{5}$ Once a wage offer is received by either spouse, it will be accepted if it results in a gain in lifetime utility (i.e., $\Omega(w)-U>0$ ), otherwise it will be rejected.

The value function of a worker-searcher couple is somewhat more involved. As can be seen in equation (6), if a couple receives a wage offer (which now arrives at rate $\alpha$, since only one spouse is unemployed), three choices now face the couple. First, the unemployed spouse can reject the offer, in which case there is no change in the value. Second, the unemployed spouse can accept the job offer and both spouses become employed, which increases the value by $T\left(w_{1}, w_{2}\right)-\Omega\left(w_{1}\right)$. Third, and finally, the unemployed spouse can accept the job offer and the employed spouse simultaneously quits his job and starts searching for a better one.

As we shall see below, this third case is the first important difference between the joint-search problem and the single-agent search problem. In the single-search problem, once an agent accepts a job offer, she will never choose to quit her job. This is because an agent strictly prefers being employed to searching at any wage offer higher than the reservation wage. Because the environment is stationary, the agent will face the same wage offer distribution upon quitting and will have the same reservation wage. As a result, a single employed agent will never quit, even if he is given the opportunity. In contrast, in the joint-search problem, the reservation wage of each spouse depends on the income of the partner. When this income grows - for example, because of a transition from unemployment to employment - the reservation wage of the previously employed spouse may also increase, which could lead to exercising the quit option. We return to this point below and discuss it in more detail.

\footnotetext{
${ }^{5}$ Because time is continuous, the probability of both spouses receiving offers simultaneously is negligible and is hence ignored.
} 


\subsection{Characterizing the couple's decisions}

Before we begin characterizing the solution to the problem, we state the following useful lemma. We refer to Appendix A for all the proofs and derivations.

Lemma $1 \Omega$ is a strictly increasing function, i.e., $\Omega^{\prime}(w)>0$ for all $w \in[0, \infty)$.

We are now ready to characterize the couple's search behavior. First, for a dual-searcher couple, the reservation wage - which is the same for both spouses by symmetry - is denoted by $w^{* *}$ and is determined by the equation

$$
\Omega\left(w^{* *}\right)=U
$$

Because $U$ is a constant and $\Omega$ is a strictly increasing function (Lemma 1 ), $w^{* *}$ is a singleton.

A worker-searcher couple has two decisions to make. The first decision is whether to accept the job offer to the unemployed spouse (say, spouse 2) or not. The second decision, conditional on accepting, is whether the employed spouse (spouse 1) should quit his job or not. Let the current wage of the employed spouse be $w_{1}$ and denote the wage offer to the unemployed spouse by $w_{2} \cdot{ }^{6}$

Accept/reject decision. Let us begin by supposing that it is not optimal to exercise the quit option upon acceptance, $T\left(w_{1}, w_{2}\right)>\Omega\left(w_{2}\right)$. In this case, a job offer with wage $w_{2}$ will be accepted when $T\left(w_{1}, w_{2}\right) \geq \Omega\left(w_{1}\right)$. Formally, the associated reservation wage function $\phi\left(w_{1}\right)$ solves

$$
T\left(w_{1}, \phi\left(w_{1}\right)\right)=\Omega\left(w_{1}\right)
$$

Suppose now instead that it is optimal to exercise the quit option upon acceptance, $\Omega\left(w_{2}\right) \geq$ $T\left(w_{1}, w_{2}\right)$. Then, the job offer will be accepted when $\Omega\left(w_{2}\right) \geq \Omega\left(w_{1}\right)$, which implies the reservation rule

$$
\Omega\left(\phi\left(w_{1}\right)\right)=\Omega\left(w_{1}\right) .
$$

Given the strict monotonicity of $\Omega$, the reservation wage rule is very simple: accept the new offer (and the other spouse will quit the existing job) whenever $w_{2} \geq w_{1}$. The worker-searcher reservation wage function $\phi(\cdot)$ is therefore piecewise, being composed of (8) and (9) in different ranges of the domain for $w_{1}$. The kink of this piecewise function, which always lies on the 45 degree line of the $\left(w_{1}, w_{2}\right)$ space, plays a special role in characterizing the behavior of the couple. We denote this point by $(\hat{w}, \hat{w})$, and formally it satisfies: $T(\hat{w}, \phi(\hat{w}))=\Omega(\hat{w})=\Omega(\phi(\hat{w})) \cdot{ }^{7}$ Since $r T(\hat{w}, \hat{w})=u(2 \hat{w}), \hat{w}$ solves

$$
u(2 \hat{w})=\Omega(\hat{w}) .
$$

\footnotetext{
${ }^{6}$ To better understand the optimal choices of the couple, it is instructive to treat the accept/reject decision of the unemployed spouse and the stay/quit decision of the employed spouse as two separate choices (albeit the couple makes them simultaneously).

${ }^{7}$ Given some further assumptions about the preferences, it will be clear that $\hat{w}$ is unique.
} 
Stay/quit decision. It remains to characterize the quitting decision. If $T\left(w_{1}, w_{2}\right) \leq \Omega\left(w_{2}\right)$, it is optimal for the employed spouse to quit his job when the unemployed spouse accepts her job offer (that is, this choice yields higher utility than would be the case if he stayed at his job and the couple became a dual-worker couple). This inequality implies the indifference condition:

$$
T\left(w_{1}, \varphi\left(w_{1}\right)\right)=\Omega\left(\varphi\left(w_{1}\right)\right) .
$$

Two important properties of $\varphi$ should be noted. First, $\varphi$ is not necessarily a function; it may be a correspondence. Second, $\varphi$ is the inverse of that piece of the $\phi$ function defined by (8). This is easily seen. By symmetry of $T$, from (8) we have that $T\left(\phi\left(w_{1}\right), w_{1}\right)=\Omega\left(w_{1}\right)$, or $T\left(w_{2}, \phi^{-1}\left(w_{2}\right)\right)=$ $\Omega\left(\phi^{-1}\left(w_{2}\right)\right)$, which compared to (11) yields the desired result.

Since $\varphi=\phi^{-1}$, then $\varphi$ will also cross the function $\phi$ on the 45-degree line at the point $\hat{w}$. Therefore, $\hat{w}$ is the highest wage level at which the unemployed spouse is indifferent between accepting and rejecting her offer and the employed partner is indifferent between keeping and quitting his job. To emphasize this feature, we refer to $\hat{w}$ as the "double indifference point."

In what follows, we characterize the optimal strategy of the couple in the $\left(w_{1}, w_{2}\right)$ space. This means establishing the ranking between $w^{* *}$ and $\hat{w}$, especially in relation to the single-agent reservation wage $w^{*}$ and studying the function $\phi$. Once we have characterized the shape of $\phi$, that of $\phi^{-1}$ follows immediately. Overall, these different reservation rules will divide the $\left(w_{1}, w_{2}\right)$ into four regions: one in which both spouses work, one where both spouses search, and the remaining two regions in which spouse 1 (2) searches and spouse 2 (1) works.

\subsection{Risk neutrality}

As will become clear below, risk aversion is central to our analysis. To provide a benchmark, we begin by presenting the risk-neutral case, then turn to the results with risk-averse agents.

Proposition 1 [Risk neutrality] With risk-neutral preferences, i.e., $u^{\prime \prime}=0$, the joint-search problem reduces to two independent single-search problems. Specifically, the value functions are

$$
\begin{aligned}
T\left(w_{1}, w_{2}\right) & =W\left(w_{1}\right)+W\left(w_{2}\right), \\
U & =2 V, \\
\Omega\left(w_{1}\right) & =V+W\left(w_{1}\right) .
\end{aligned}
$$

The reservation wage function $\phi(\cdot)$ of the worker-searcher couple is constant and is equal to the reservation wage value of a dual-searcher couple (regardless of the wage of the employed spouse), which, in turn, equals the reservation value in the single-search problem, i.e., $\phi\left(w_{1}\right)=w^{* *}=w^{*}$.

Figure 1 shows the relevant reservation wage functions in the $\left(w_{1}, w_{2}\right)$ space, where $w_{1}$ and $w_{2}$ are the wages of spouses 1 and 2, respectively. In this paper, when we discuss worker-searcher couples, we will think of spouse 1 as the employed spouse and display his wage $w_{1}$ on the horizontal 
Figure 1: Reservation Wage Functions with Risk Neutrality

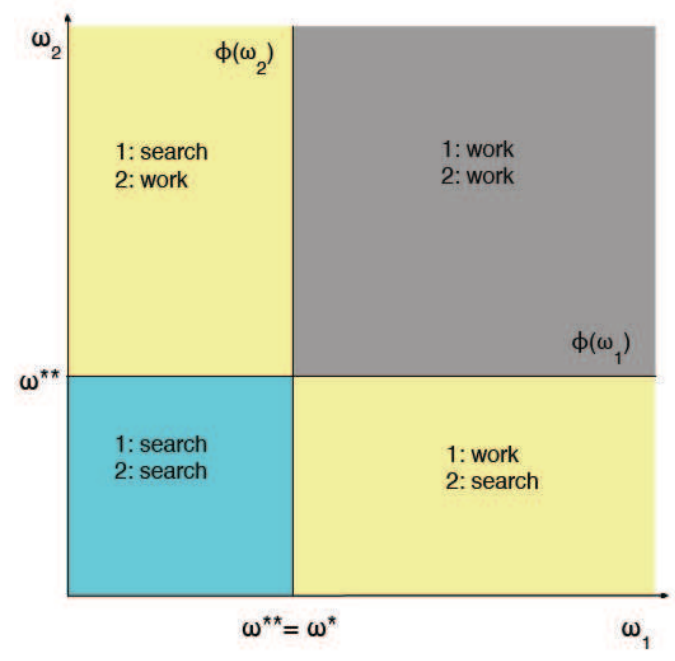

axis, and think of spouse 2 as the unemployed spouse and display her wage offer $\left(w_{2}\right)$ on the vertical axis.

As stated in the proposition, the reservation wage function of a worker-searcher couple, $\phi\left(w_{1}\right)$ is simply the horizontal line at $w^{* *}$. Similarly, the reservation wage for the quit decision is the inverse (mirror image with respect to the 45-degree line) of $\phi\left(w_{1}\right)$ and is shown by the vertical line at $w_{1}=w^{* *}$. The intersection of these two lines gives rise to four regions, in which the couple displays distinct behaviors.

No wage below $w^{* *}$ is ever accepted by a dual-searcher couple in this model. Therefore, a worker-searcher couple will never be observed with a wage below $w^{* *}$. As a result, the only wage values relevant for the employed spouse are above the $\phi\left(w_{1}\right)$ function. If the unemployed spouse receives a wage offer $w_{2}<w^{* *}$, she rejects the offer and continues to search. If she receives an offer higher than $w^{* *}$, she accepts the offer. At this point the employed partner retains his job, and the couple becomes a dual-worker couple.

For things to get interesting, risk aversion must be brought to the fore. In Section 5, we will also see that when the job-search process takes place in multiple locations and there is a cost of living separately for the couple, then even in the risk-neutral case there are important deviations from the single-agent search problem.

\subsection{Risk aversion}

To introduce risk aversion into the present framework, we employ preferences in the HARA (hyperbolic absolute risk aversion) class. This class encompasses several well-known utility functions as special cases. Formally, HARA preferences are defined as the family of utility functions that have 
linear risk tolerance: $-u^{\prime}(c) / u^{\prime \prime}(c)=a+\tau c$, where $a$ and $\tau$ are parameters. ${ }^{8}$

This class can be further divided into three subclasses depending on the sign of $\tau$. First, when $\tau \equiv 0$, then risk tolerance (and hence absolute risk aversion) is independent of consumption level. This case corresponds to constant absolute risk aversion (CARA) preferences, also known as exponential utility $u(c)=-e^{-a c} / a$. Second, if $\tau>0$ then absolute risk tolerance is increasingand therefore risk aversion is decreasing - with consumption, which is the decreasing absolute risk aversion (DARA) case. A well-known special case of this class is the constant relative risk aversion (CRRA) utility: $u(c)=c^{1-\rho} /(1-\rho)$, which obtains when $a \equiv 0$ and $\tau=1 / \rho>0$. Finally, if $\tau<0$ risk aversion increases with consumption, and this class is referred to as increasing absolute risk aversion (IARA). A special case of this class is quadratic utility: $u(c)=-(a-c)^{2}$, which obtains when $\tau=-1$.

\subsubsection{CARA utility}

We first characterize the search behavior of a couple under CARA preferences and show that it serves as the watershed for the description of search behavior under HARA preferences. The following proposition summarizes the optimal search strategy of the couple.

Proposition 2 [CARA utility] With CARA preferences, the search behavior of a couple can be characterized as follows:

(i) The reservation wage value of a dual-searcher couple is strictly smaller than the reservation wage of a single agent: $w^{* *}<w^{*}=\hat{w}$.

(ii) The reservation wage function of a worker-searcher couple is piecewise linear in the employed spouse's wage

$$
\phi\left(w_{1}\right)= \begin{cases}w_{1} & \text { if } w_{1} \in\left[w^{* *}, w^{*}\right) \\ w^{*} & \text { if } w_{1} \geq w^{*}\end{cases}
$$

Figure 2 provides a visual summary of the contents of this proposition in the wage space. Three important remarks are in order.

First, the dual-searcher couple is less choosy than the single agent $\left(w^{* *}<w^{*}\right)$. With risk aversion, the optimal search strategy involves a trade-off between lifetime income maximization and the desire for consumption smoothing. The former force pushes up the reservation wage; the second pulls it down because risk-averse agents particularly dislike the low income state (unemployment). The dual-searcher couple can use income pooling to its advantage: it initially accepts a lower wage offer (to smooth consumption across states) while, at the same time, not giving up completely the search option (to increase lifetime income) that remains available to the other spouse. In contrast, when the single agent accepts his job, he gives up the search option for good, which induces him to

\footnotetext{
${ }^{8}$ Risk tolerance is defined as the reciprocal of Pratt's measure of "absolute risk aversion." Thus, if risk tolerance is linear, risk aversion is hyperbolic.
} 
Figure 2: Reservation Wage Functions with CARA Preferences

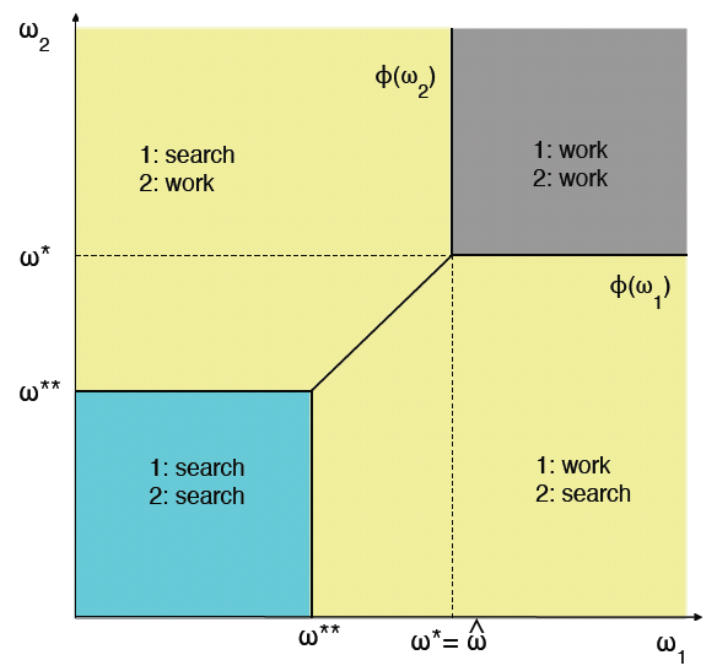

be more picky at the start. Notice that joint search plays a role similar to on-the-job search in the absence of it. We return to this point later.

Second, for a worker-searcher couple earning a wage greater than $w^{*}$, the reservation wage function is constant and equal to $w^{*}$, the reservation wage value of the single unemployed agent. This is because with CARA utility, agents' attitude toward risk does not change with the consumption (and hence wage) level. As the wage of the employed spouse increases, the couple's absolute risk aversion remains unaffected, implying a constant reservation wage for the unemployed partner.

Although Appendix A contains a formal proof of this result, it is instructive to sketch the argument behind the proof here. To this end, begin by conjecturing that there is a wage level (to be determined below) above which it is never optimal to exercise the quit option. In this wage range, equation (6) simplifies to

$$
r \Omega\left(w_{1}\right)=u\left(w_{1}+b\right)+\alpha \int_{\phi\left(w_{1}\right)}\left[T\left(w_{1}, w_{2}\right)-\Omega\left(w_{1}\right)\right] d F\left(w_{2}\right) .
$$

Substituting out $\Omega$ and $T$ (using equations (4) and (8)) shows that the reservation wage function for the unemployed spouse must satisfy

$$
u\left(w_{1}+\phi\left(w_{1}\right)\right)=u\left(w_{1}+b\right)+\frac{\alpha}{r} \int_{\phi\left(w_{1}\right)}\left[u\left(w_{1}+w_{2}\right)-u\left(w_{1}+\phi\left(w_{1}\right)\right)\right] d F\left(w_{2}\right) .
$$

Finally, with exponential utility we have: $u\left(w_{1}+w_{2}\right)=-u\left(w_{1}\right) u\left(w_{2}\right)$, which simplifies the previous equation by eliminating the dependence on $w_{1}$ :

$$
u\left(\phi\left(w_{1}\right)\right)=u(b)+\frac{\alpha}{r} \int_{\phi\left(w_{1}\right)}\left[u\left(w_{2}\right)-u\left(\phi\left(w_{1}\right)\right)\right] d F\left(w_{2}\right) .
$$

Notice that, since the dependence on the employed partner wage $w_{1}$ ceases, this condition becomes exactly the same as the one in the single-search problem (equation (3)) and is thus satisfied 
by the constant reservation function: $\phi\left(w_{1}\right)=w^{*}$. Moreover, when $\phi$ is a constant function, its inverse is $\phi^{-1}\left(w_{1}\right)=\infty$. Thus, there is no wage offer $w_{2}$ that can exceed $\phi^{-1}\left(w_{1}\right)$ to trigger a quit, which in turn verifies our conjecture that the employed spouse does not quit in the wage range $w_{1}>w^{*}$.

Breadwinner cycle. A third remark, and a key implication of the proposition, is that the reservation wage value of a dual-searcher couple $w^{* *}$, being strictly smaller than $w^{*}$, activates the region in which $\phi\left(w_{1}\right)$ is strictly increasing and in turn gives rise to the "breadwinner cycle." Suppose that $w_{1} \in\left(w^{* *}, w^{*}\right)$ and the unemployed spouse receives a wage offer $w_{2}>w_{1}=\phi\left(w_{1}\right)$, where the equality only holds in the specified region $\left(w^{* *}, w^{*}\right)$. Because the offer is higher than the worker-searcher couple's reservation wage, the unemployed spouse accepts the offer and becomes employed. However, accepting this wage offer also implies $w_{2}>\phi^{-1}\left(w_{1}\right)=w_{1}$, which, in turn, implies $w_{1}<\phi\left(w_{2}\right)$. This means that the threshold for the first spouse to keep his job now exceeds his current wage, and he will quit.

As a result, spouses simultaneously switch roles and transit from a worker-searcher couple into another worker-searcher couple with a higher wage level. This process repeats itself over and over again as long as the employed spouse's wage stays in the range $\left(w^{* *}, w^{*}\right)$, although of course the identity of the employed spouse (i.e., the breadwinner) alternates. Once both spouses have job offers beyond $w^{*}$ in hand, the breadwinner cycle stops and so does the search process.

To provide a better sense of how the breadwinner cycle works, Figure 3 plots the simulated wage paths of a couple when spouses behave optimally under joint search (lines with markers) and for the same individuals when they act as two unrelated singles (dashed lines). To make the comparison meaningful, the paths are generated using the same simulated sequence of job offers for each individual when he/she is single and when they act as a couple. First, the breadwinner cycle is seen clearly here as spouses alternate between who works and who searches depending on the offers received by each spouse. Instead, when faced with the same job offer sequence, the same individuals simply accept a job (agent 1 in period 33 and agent 2 in period 60) and then never quit. Second, in period 29, agent 2 accepts a wage offer of 1.02 when she is part of a couple but rejects the same offer when acting as single, reflecting the fact that dual-searcher couples have a lower reservation wage than single agents. The opposite happens in period 60 when agent 2 accepts a job offer of 1.08 as single but turns it down when married, reflecting the fact that worker-searcher couples are more picky in accepting job offers than single agents. It is also easy to see that in the long run, the wages of both agents are higher under joint search - thanks to the breadwinner cycle, even though it may require a longer search process. Below we provide some illustrative simulations to show that, on average, joint search always yields a higher lifetime income (i.e., even when later wages are discounted). 
Figure 3: Simulated Wage Paths for a Couple and for the Same Individuals When They Are Single
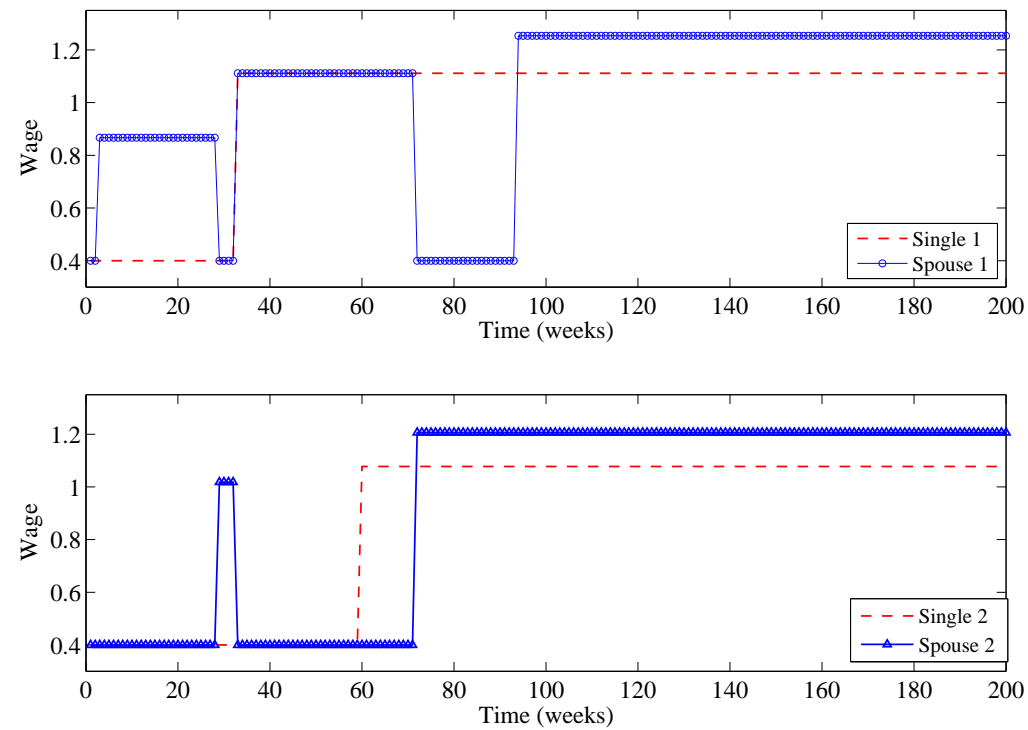

\subsubsection{DARA utility}

As noted earlier, DARA utility is of special interest, since it encompasses the well-known and commonly used CRRA utility specification $u(c)=c^{1-\rho} /(1-\rho)$. More generally, the coefficient of absolute risk aversion with DARA preferences is $-u^{\prime \prime}(c) / u^{\prime}(c)=\rho /(c+\rho a)$, which decreases with the consumption (and hence the wage) level. The following proposition characterizes the optimal search strategy for couples with DARA preferences.

Proposition 3 [DARA utility] With DARA preferences, the search behavior of a couple can be characterized as follows:

(i) The reservation wage value of a dual-searcher couple satisfies: $w^{* *}<\hat{w}$ (with $\left.w^{*}<\hat{w}\right)$, which implies that the breadwinner cycle exists.

(ii) The reservation wage function of a worker-searcher couple has the following properties: for $w_{1}<\hat{w}, \phi\left(w_{1}\right)=w_{1}$, and for $w_{1} \geq \hat{w}, \phi\left(w_{1}\right)$ is strictly increasing with $\phi^{\prime}<1$.

Figure 4 provides a graphical representation of the reservation wage functions associated with the DARA case. Unlike the CARA case, the reservation function of the worker-searcher couple is now increasing with the wage of the employed spouse at all wage levels. This is because with decreasing absolute risk aversion, a couple becomes less concerned about smoothing consumption as household resources increase and, consequently, becomes more picky in its job search.

Again, it is useful to sketch the main idea behind the proof, which proceeds by assuming a nonincreasing reservation wage function and showing that this leads to a contradiction. Specifically, 
begin by supposing that $\phi^{\prime}(\cdot) \leq 0$ beyond a certain wage threshold. In this range, the quit option will not be exercised, so we have

$$
u\left(w_{1}+\phi\left(w_{1}\right)\right)-u\left(w_{1}+b\right)=\frac{\alpha}{r} \int_{\phi\left(w_{1}\right)}\left[u\left(w_{1}+w_{2}\right)-u\left(w_{1}+\phi\left(w_{1}\right)\right)\right] d F\left(w_{2}\right),
$$

which is identical to the CARA case, except that we have rearranged the terms here for convenience. Divide both sides by the left-hand side:

$$
1=\frac{\alpha}{r} \int_{\phi\left(w_{1}\right)}\left[\frac{u\left(w_{1}+w_{2}\right)-u\left(w_{1}+\phi\left(w_{1}\right)\right)}{u\left(w_{1}+\phi\left(w_{1}\right)\right)-u\left(w_{1}+b\right)}\right] d F\left(w_{2}\right) .
$$

Now consider a wage level $\widetilde{w}_{1}>w_{1}$ and replace $\phi\left(w_{1}\right)$ on the right-hand side with $\phi\left(\widetilde{w}_{1}\right)$ (which is smaller, by our hypothesis that $\left.\phi^{\prime}(\cdot) \leq 0\right)$. Then we have

$$
1 \leq \frac{\alpha}{r} \int_{\phi\left(\tilde{w}_{1}\right)}\left[\frac{u\left(w_{1}+w_{2}\right)-u\left(w_{1}+\phi\left(\tilde{w}_{1}\right)\right)}{u\left(w_{1}+\phi\left(\tilde{w}_{1}\right)\right)-u\left(w_{1}+b\right)}\right] d F\left(w_{2}\right) .
$$

Next, applying a well-known result on DARA preferences established by Pratt (1964, Theorem 1 ), it can easily be shown that the following inequality holds for any $p>m>q$ and $\tilde{w}_{1}>w_{1}$ :

$$
\frac{u\left(w_{1}+p\right)-u\left(w_{1}+m\right)}{u\left(w_{1}+m\right)-u\left(w_{1}+q\right)}<\frac{u\left(\tilde{w}_{1}+p\right)-u\left(\tilde{w}_{1}+m\right)}{u\left(\tilde{w}_{1}+m\right)-u\left(\tilde{w}_{1}+q\right)} .
$$

Setting $p \equiv w_{2}, m \equiv \phi\left(\tilde{w}_{1}\right)$, and, integrating both sides over $w_{2}$, and then combining with equation (14) yields

$$
1<\frac{\alpha}{r} \int_{\phi\left(\tilde{w}_{1}\right)}\left[\frac{u\left(\tilde{w}_{1}+w_{2}\right)-u\left(\tilde{w}_{1}+\phi\left(\tilde{w}_{1}\right)\right)}{u\left(\tilde{w}_{1}+\phi\left(\tilde{w}_{1}\right)\right)-u\left(\tilde{w}_{1}+b\right)}\right] d F\left(w_{2}\right) .
$$

But notice that the right-hand side of this last expression and of equation (13) are identical (when $\tilde{w}_{1}$ is replaced with $w_{1}$ ), whereas the left-hand side of each expression is different. Therefore, we have reached a contradiction, establishing that $\phi^{\prime}\left(w_{1}\right)>0$ as stated in the proposition.

The proposition also shows that the breadwinner cycle continues to exist. In contrast to the CARA case, now the breadwinner cycle is observed over a wider range of wage values of the employed spouse. This is because, as can be seen in Figure $4, \phi$ is strictly increasing in $w_{1}$, so its inverse is not a vertical line anymore but is itself an increasing function. As a result, even when $w_{1}>\hat{w}$, a sufficiently high wage offer - one that exceeds $\phi^{-1}\left(w_{1}\right)$ — not only will be accepted by the unemployed spouse but will also trigger the employed spouse to quit. One way to understand this result is by noting that the employed spouse will quit if his reservation wage upon quitting is higher than his current wage. If $w_{2}>\phi^{-1}\left(w_{1}\right)$, this implies that upon quitting the job, the reservation wage for the currently employed spouse becomes $\phi\left(w_{2}\right)>\phi\left(\phi^{-1}\left(w_{1}\right)\right)=w_{1}$. Since this reservation wage is higher than his current wage, it is optimal for the employed spouse to quit the job. Note that only if the wage offer is $w_{2} \in\left(\phi\left(w_{1}\right), \phi^{-1}\left(w_{1}\right)\right)$, the job offer is accepted without triggering a quit.

Finally, there is an interesting analogy between our result that $\phi^{\prime}\left(w_{1}\right)>0$ with DARA and a recent finding in search models of marriage formation. Consider a special case of our model 
Figure 4: Reservation Wage Functions with DARA Preferences

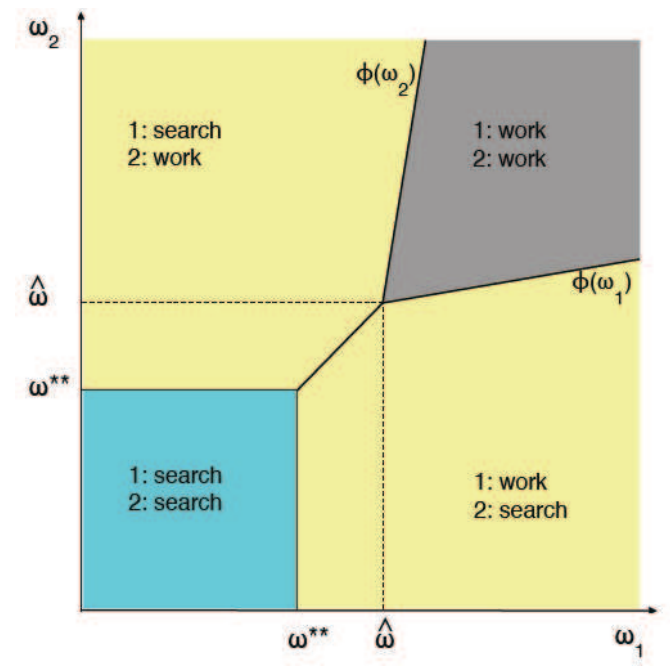

where unemployment income is zero and where job quits are not allowed. A worker-searcher couple can be thought of as a single individual with endowment $w_{1}$ looking for another individual with endowment $w_{2}$ in order to form a marriage with total endowment $w_{1}+w_{2}$ (e.g., Visschers, 2006). In this environment, if individuals (single or married) use DARA utility to value endowments, positive assortative matching along the $w$ dimension occurs. This means precisely that $\phi^{\prime}\left(w_{1}\right)>0$.

\subsubsection{IARA utility}

We now turn to IARA preferences, which display increasing absolute risk aversion as consumption increases. One well-known example of IARA preferences is quadratic utility: $-(\bar{c}-c)^{2}$, where $\bar{c}$ is the bliss point.

Proposition 4 [IARA utility] With IARA preferences, the search behavior of a couple can be characterized as follows:

(i) The reservation wage value of a dual-searcher couple satisfies: $w^{* *}<\hat{w}$, which implies that the breadwinner cycle exists.

(ii) The reservation wage function of a worker-searcher couple has the following properties: for $w_{1}<\hat{w}, \phi\left(w_{1}\right)=w_{1}$, and for $w_{1} \geq \hat{w}, \phi\left(w_{1}\right)$ is strictly decreasing.

The proof of the proposition is very similar to the DARA case and is therefore omitted for brevity. ${ }^{9}$ Figure 5 graphically shows the IARA case.

\footnotetext{
${ }^{9}$ The logic of the proof is as follows. Conjecture that beyond some wage level $w_{1}$ the employed worker never quits, and verify the guess by using the property of IARA (also shown by Pratt (1964)) corresponding to (15), but with the inequality reversed. The rest of the proof is exactly as for the DARA case.
} 
Figure 5: Reservation Wage Functions with IARA Preferences

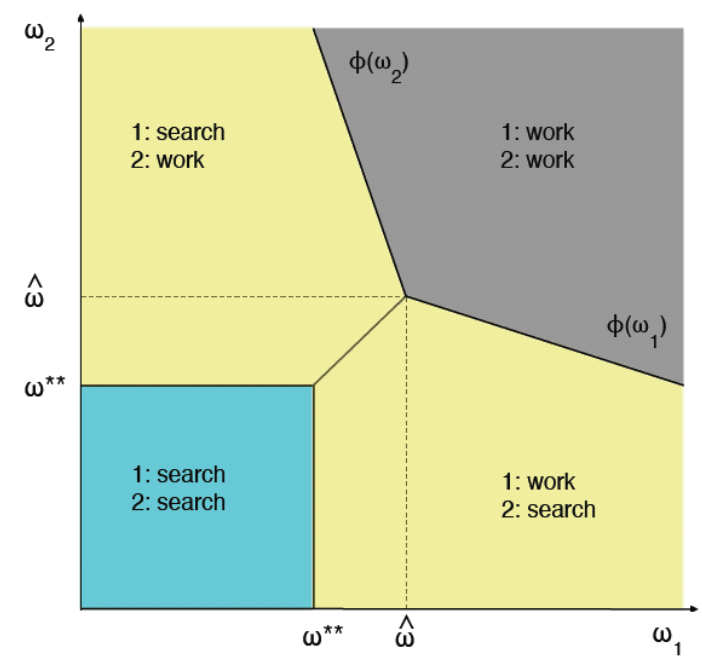

The reservation wage function $\phi$ of a worker-searcher couple deviates from the CARA benchmark in the opposite direction of the DARA case. In particular, beyond wage level $\hat{w}$, the reservation function $\phi\left(w_{1}\right)$ is decreasing in $w_{1}$, whereas it was increasing in the DARA case. As a result, if the unemployed spouse receives a wage offer higher than $\phi^{-1}\left(w_{1}\right)$, she accepts the offer, the employed stays in the job, and both stay employed forever. If the wage offer instead is between $\phi\left(w_{1}\right)$ and $\phi^{-1}\left(w_{1}\right)$, then the job offer is accepted followed by a quit by the employed spouse. This behavior is the opposite of the DARA case where high wage offers resulted in quit and intermediate wages did not. Moreover, now the breadwinner cycle never happens at wage levels $w_{1}>\hat{w}$. This is a direct consequence of increasing absolute risk aversion, which induces a couple to become less choosy when searching as its wage level rises.

Before concluding this section, it is interesting to ask why it is that the absolute risk aversion determines the properties of joint-search behavior (as shown in the propositions so far), as opposed to, for example, relative risk aversion. The reason is that individuals are drawing wage offers from the same probability distribution regardless of the current wage earnings of the couple. As a result, the uncertainty they face is fixed and is determined by the dispersion in the wage offer distribution, making the attitudes of a couple toward a fixed amount of risk - and therefore, the absolute risk aversion - the relevant measure. ${ }^{10}$

\subsection{An isomorphism: search with multiple job holdings}

The joint-search framework analyzed so far is isomorphic to a search model with a single agent who can hold multiple jobs at the same time. To see this, suppose that the time endowment of a worker can be divided into two subperiods (e.g., day shift and night shift). The single agent can be (i)

\footnotetext{
${ }^{10}$ If, for example, individuals were to draw wage offers from a distribution that depended on the current wage of a couple, this would make relative risk aversion relevant as well.
} 
unemployed and searching for his first job while enjoying $2 b$ units of home production, (ii) working one job at wage $w_{1}$ while searching for a second one, or (iii) holding two jobs with wages $w_{1}$ and $w_{2}$. It is easy to see that the problem faced by this individual is exactly given by the same equations $\left((4),(5)\right.$, and (6)) for the joint-search model and therefore has the same solution. ${ }^{11}$

Consequently, for example, when the agent works in one job and gets a second job offer with a sufficiently high wage offer, he will accept the offer and simultaneously quit the first job to search for a better one. In this case, it is not the breadwinner that alternates, but the jobs that the worker juggles over time.

\section{Extensions}

The baseline joint-search framework we developed up to this point is intended to provide the simplest possible deviation from the well-known single-search problem. Despite being highly stylized, this simple model illustrated some new and potentially important mechanisms that are not operational in the single-agent search problem.

In this section, we enrich this basic model in four empirically relevant directions. First, we allow for nonparticipation. Second, we add on-the-job search. Third, we allow for exogenous job separations. Fourth, we allow households to borrow in financial markets. In a number of special cases, we are able to fully characterize the reservation strategies of the couple. We also simulate a calibrated version of our model to analyze the differences between a single-agent search economy and the joint-search economy in more general cases.

\subsection{Nonparticipation}

We now extend the two-state model of the labor market we adopted so far to a three-state model where either spouse can choose nonparticipation. Nonparticipation means that the individual does not search for a job opportunity. Consistently with the rest of the paper, where we interpret $b$ as income, we model the benefit associated to nonparticipation as $z>b$ consumption units (e.g., through home production).

We need to redefine some of the value functions for the couple. First, consider the two configurations where (i) both spouses are outside the labor force, and (ii) one spouse does not participate and the other is employed at wage $w$. Because of the absence of randomness, both of these states are absorbing, as they are for the dual-worker couple. Therefore, we can denote the flow value for a couple in the first state as $r T(z, z)=u(2 z)$ and the flow value for a couple in the second state as $r T\left(z, w_{2}\right)=u\left(z+w_{2}\right)$. This formulation shows that nonparticipation is equivalent to a job opportunity which pays $z$ (and entails foregoing search) that is always available to the worker.

\footnotetext{
${ }^{11}$ There is a further implicit assumption here: the arrival rate of job offers is proportional to the nonworking time of the agent (that is, $2 \alpha$ when unemployed and $\alpha$ when working one job).
} 
The flow value for the state where one spouse does not participate and the other is unemployed is

$$
r \Omega(z)=u(z+b)+\alpha \int \max \left\{T\left(z, w_{2}\right)-\Omega(z), \Omega\left(w_{2}\right)-\Omega(z), 0\right\} d F\left(w_{2}\right),
$$

where the equation shows that upon spouse 2 accepting a job offer, spouse 1 can either remain out of the labor force, or start searching.

The value of a dual-searcher couple becomes

$$
r U=u(2 b)+2 \alpha \int \max \{T(z, w)-U, \Omega(w)-U, 0\} d F(w),
$$

which shows that upon either spouse finding a job, the other has the choice of either continuing to search or dropping out of the labor force.

Finally, the value of a worker-searcher couple where spouse 1 is employed is

$$
r \Omega\left(w_{1}\right)=u\left(w_{1}+b\right)+\alpha \int \max \left\{T\left(w_{1}, w_{2}\right)-\Omega\left(w_{1}\right), \Omega\left(w_{2}\right)-\Omega\left(w_{1}\right), 0\right\} d F\left(w_{2}\right) .
$$

The choices available to the couple when spouse 2 finds an acceptable job offer are either spouse 1 remains employed at $w_{1}$ or spouse 1 quits into unemployment. This state will arise only for $w_{1}>z$, since $z$ is always available. ${ }^{12}$ As clear from this equation, once the couple reaches this state, nonparticipation will never occur thereafter. This observation is important, since it means that our definitions of $w^{* *}, \hat{w}$, and $\phi(w)$ remain unchanged and these functions are independent of $z$.

Proposition 5 [Joint search with nonparticipation] With either CARA or DARA preferences, the search behavior of a couple can be characterized as follows:

(i) If $z \leq w^{* *}$, the search strategy of the couple is unaffected by nonparticipation, since the latter option is never optimal.

(ii) If $w^{* *}<z<\hat{w}$, dual search is never optimal, and whenever a spouse is unemployed, the other is either employed or a nonparticipant. The reservation wage of a nonparticipant-searcher couple is $z$, and the reservation function of a worker-searcher couple is the same function $\phi(w)$ as in the absence of nonparticipation.

(iii) If $z \geq \hat{w}$, nonparticipation is an absorbing state for both spouses, and search is never optimal.

Since nonparticipation is like a job offer at wage $z$ that is always available, if $z<w^{* *}$ such offer is never accepted by a dual-searcher couple, and nonparticipation is never optimal. When $w^{* *}<z<\hat{w}$, then consumption-smoothing motives induce the jobless couple to move one of its members into nonparticipation - say, spouse 1 -while spouse 2 is searching with reservation wage

\footnotetext{
${ }^{12}$ More precisely, there is a third option in the max operator which is, theoretically, available to spouse 1: quitting into nonparticipation and accepting $z$ forever with a gain $T\left(z, w_{2}\right)-\Omega\left(w_{1}\right)$ for the couple. However, the wage gain associated with spouse 1 keeping his/her current job, $T\left(w_{1}, w_{2}\right)-\Omega\left(w_{1}\right)$, must be larger, since previously spouse 1 has accepted $w_{1}$ when $z$ was available.
} 
$\phi(z)=z$. As soon as a wage offer $w_{2}$ larger than $z$ arrives, the unemployed spouse accepts the job and spouse 1 switches into unemployment, since search is equivalent to being employed at $\phi\left(w_{2}\right) \geq \hat{w}>z$. The first inequality follows from the CARA or DARA assumption under which $\phi$ is a nondecreasing function. It is immediate that if $z \geq \hat{w}$, then both spouses exit the labor force right away and no search occurs. As soon as one chooses not to search, the other spouse reservation wage becomes $\phi(z)$, which is always smaller than $z$ in this region. As a result, nonparticipation is attractive for the other spouse as well. ${ }^{13}$

The joint-search problem is, once again, different from the single-agent search problem. For example, in the CARA case where $\hat{w}=w^{*}$, we can establish that under configuration (ii), a single agent would be always searching and nonemployment would never arise, whereas a jobless couple would choose to move one spouse out of the labor force for consumption-smoothing purposes.

Finally, note that under this representation of nonparticipation as income, we obtain a stark result: the couple will never be in a state where one spouse works and the other is a nonparticipant. ${ }^{14}$ However, the next lemma shows that under IARA, the worker-nonparticipant configuration may be optimal for the couple. Intuitively, since $\phi$ is decreasing in $w$ (recall Figure 5), a wage offer $\tilde{w}$ could arrive - say, to a dual searcher couple - that is, high enough to induce the couple to accept the offer and set the new reservation wage for the unemployed member to $\phi(\tilde{w})<z$. Thus, the unemployed member immediately exits the labor force.

Lemma 2 [Non participation with IARA preferences] With IARA preferences, both dual searcher couples and non-participant searcher couples can become non-participant worker couples.

\subsection{On-the-job search}

Suppose that agents can search both off and on the job. During unemployment, they draw a new wage from $F(w)$ at rate $\alpha_{u}$, whereas during employment they sample new job offers from the same distribution $F$ at rate $\alpha_{e}$. What we develop below is, essentially, a version of the Burdett (1978) wage ladder model with couples. The flow value functions in this case are

$$
\begin{gathered}
r U=u(2 b)+2 \alpha_{u} \int \max \{\Omega(w)-U, 0\} d F(w), \\
r \Omega\left(w_{1}\right)=u\left(w_{1}+b\right)+\alpha_{u} \int \max \left\{T\left(w_{1}, w_{2}\right)-\Omega\left(w_{1}\right), \Omega\left(w_{2}\right)-\Omega\left(w_{1}\right), 0\right\} d F\left(w_{2}\right) \\
+\alpha_{e} \int \max \left\{\Omega\left(w_{1}^{\prime}\right)-\Omega\left(w_{1}\right), 0\right\} d F\left(w_{1}^{\prime}\right),
\end{gathered}
$$

\footnotetext{
${ }^{13}$ In order to save space, we do not represent graphically this version of the model. It is immediate to see that one can generate the graph with nonparticipation corresponding to case (ii) by overlapping a squared area with coordinates $(x, y)=(z, z)$ to Figures 2 and 4 . This area would substitute the dual-searcher couple with the nonparticipant-searcher couple.

${ }^{14}$ If preferences are CARA or DARA, this state can only occur when wealth effects on labor supply are active (as in Burdett and Mortensen, 1977), or in presence of asymmetries between spouses.
} 


$$
\begin{aligned}
r T\left(w_{1}, w_{2}\right) & =u\left(w_{1}+w_{2}\right)+\alpha_{e} \int \max \left\{T\left(w_{1}^{\prime}, w_{2}\right)-T\left(w_{1}, w_{2}\right), 0\right\} d F\left(w_{1}^{\prime}\right) \\
& +\alpha_{e} \int \max \left\{T\left(w_{1}, w_{2}^{\prime}\right)-T\left(w_{1}, w_{2}\right), 0\right\} d F\left(w_{2}^{\prime}\right) .
\end{aligned}
$$

We continue to denote the reservation wage of the dual-searcher couple as $w^{* *}$ and the reservation wage of the unemployed spouse in the worker-searcher couple as $\phi\left(w_{1}\right)$. We now have a new reservation function, that of the employed spouse (in the dual-worker couple and in the worker-searcher couple) which we denote by $\eta\left(w_{i}\right)$.

It is intuitive (and can be proved easily) that under risk neutrality the joint-search problem coincides with the problem of the single agent regardless of offer arrival rates. Below, we prove another equivalence result that holds for any risk-averse utility function but for the special case of symmetric offer arrival rates $\alpha_{u}=\alpha_{e}$, i.e., when search is equally effective on and off the job.

Proposition 6 [On-the-job search with symmetric arrival rates] If $\alpha_{u}=\alpha_{e}$, the joint-search problem yields the same solution as the single-agent search problem, even with concave preferences. Specifically, $w^{* *}=w^{*}=b, \phi\left(w_{1}\right)=w^{* *}$ and $\eta\left(w_{i}\right)=w_{i}$ for $i=1,2$.

To understand this equivalence result, notice that one way to think about joint search is that it provides a way to climb the wage ladder for the couple even without on-the-job search: when a dual-searcher couple accepts the first job offer, it continues to receive offers, albeit at a reduced arrival rate. Therefore, one can view joint search as a "costly" version of on-the-job search. The cost comes from the fact that, absent on the job search, in order to keep the search option active, the pair must remain a worker-searcher couple and must not enjoy the full wage earnings of a dual-worker couple as it would be capable of doing with on-the-job search. As a result, when on-the-job search is explicitly introduced and the offer arrival rate is equal across employment states, it completely neutralizes the benefits of joint search and makes the problem equivalent to that of a single agent. The solution is then simply that the unemployed partner should accept any offer above $b$ and the spouse employed at $w_{1}$ any wage above its current one.

The preceding proposition that characterizes joint-search behavior when $\alpha_{u}=\alpha_{e}$ provides an alternative benchmark to the baseline model, which had $\alpha_{u}>\alpha_{e} \equiv 0$. The empirically relevant case is probably in between these two benchmarks, in which case joint-search behavior continues to be qualitatively different from single search (for example, the breadwinner cycle will be active). We provide some simulations in Section 4.5 below to illustrate these intermediate cases.

Empirically, one would expect the network of labor market contacts and opportunities (and hence the effectiveness of on-the-job search) to increase with skill level and with occupational experience. As a result, deviations from single-agent search should be more evident among young, inexperienced, and uneducated couples. 


\subsection{Exogenous separations}

As discussed above, in the absence of exogenous separations, agents optimally choose not to accumulate assets, so a simple no-borrowing constraint ensures that agents live as hand-to-mouth consumers. This is no longer true when exogenous separation risk is introduced, because in this case accumulated assets can be used to smooth consumption when agents lose their jobs. This saving motive, however, significantly complicates the analysis. Thus, to establish some general theoretical results, we rule out storage in this section.

Suppose that jobs are exogenously lost at rate $\delta$ and that upon a job loss, workers enter unemployment. Once again, under risk neutrality it is easy to establish that the joint-search problem collapses to the single-agent problem. With risk aversion, however, this is not the case anymore. We first state the following proposition that characterizes joint-search behavior with exogenous separations and then discuss the intuition. The modifications to the value functions are immediate, so we omit them.

Proposition 7 [CARA/DARA utility with exogenous separations] With CARA or DARA preferences, no access to financial markets, and exogenous job separation, the search behavior of a couple can be characterized as follows:

(i) The reservation wage value of a dual-searcher couple satisfies: $w^{* *}<\hat{w}$ (with $\left.w^{*}<\hat{w}\right)$, which implies that the breadwinner cycle exists.

(ii) The reservation wage function of a worker-searcher couple has the following properties: for $w_{1}<\hat{w}, \phi\left(w_{1}\right)=w_{1}$, and for $w_{1} \geq \hat{w}, \phi\left(w_{1}\right)$ is strictly increasing with $\phi^{\prime}<1$.

Two remarks are in order. First, for DARA preferences, the existence of exogenous separations has qualitatively no effect on joint-search behavior, as can be seen by comparing Propositions 3 and $7{ }^{15}$ Second, and perhaps more interestingly, for CARA preferences $\phi\left(w_{1}\right)$ is no longer independent of the employed spouse's wage but is now increasing with it. In the context of joint-search, the separation risk has two separate meanings. Consider the problem of the worker-searcher couple with current wage $w_{1}$ contemplating a new job offer with wage $w_{2}$. First, there is the risk associated with the duration of the new job offered to the searching spouse. Second, there is the risk of job loss for the currently unemployed spouse. ${ }^{16}$

The first effect of exogenous separations is also present in the single-agent search model: if the expected duration of a job is lower (high $\delta$ ), the unemployed agent reduces her reservation wage for all values of $w_{1}$. However, the larger the wage $w_{1}$ of the employed spouse, the smaller this effect, since the utility value for the household of the additional wage decreases in $w_{1}$. Since $\phi\left(w_{1}\right)$ is

\footnotetext{
${ }^{15}$ The only difference is that here we explicitly rule out saving, whereas previous propositions did not require this assumption as explained before. However, apart from the stronger assumption made here, the search behavior with DARA utility is the same in the two propositions.

${ }^{16}$ In a model with spouse asymmetries in separation rates, this would be even more clear, since we would have a pair $\left(\delta_{1}, \delta_{2}\right)$ in the value functions as opposed to just $\delta$.
} 
weakly decreasing in the case $\delta=0$, with $\delta>0$ the reservation function $\phi\left(w_{1}\right)$ will become strictly increasing.

The second effect is related to the event that the currently employed spouse might lose his job. If the couple turns down the offer at hand and the job loss indeed occurs, its earnings will fall from $w_{1}+b$ to $2 b$ for a net change of $b-w_{1}<0$. Clearly, this income loss (and, therefore, the fall in consumption) is larger, the higher is the current wage of the employed spouse. If instead the couple accepts the job offer and spouse 1 loses his job, earnings will change from $w_{1}+b$ to $b+w_{2}$, for a net change of $w_{2}-w_{1}$. On the one hand, setting the reservation wage to $\phi\left(w_{1}\right)=w_{1}$ would completely insure the downside risk of spouse 1 losing his job (because then $w_{2}-w_{1} \geq 0$ ). At the same time, letting the reservation wage rise this quickly with $w_{1}$ reduces the probability of an acceptable offer and increases the probability that the searcher will still be unemployed when spouse 1 loses his job. As a result, the optimal reservation wage policy balances these two considerations to provide the best self-insurance to the couple and, consequently, have $\phi\left(w_{1}\right)$ rise with $w_{1}$, but less than one for one: $\phi^{\prime}<1 .^{17}$

\subsection{Borrowing in financial markets}

With few exceptions, search models with risk-averse agents and a borrowing-saving decision do not allow analytical solutions. ${ }^{18}$ One such exception is when preferences display CARA and agents have access to a risk-free asset. This environment has been recently used in previous work to obtain analytical results in the context of the single-agent search problem (e.g., Acemoglu and Shimer (1999), and Shimer and Werning (2008)). Following this tradition, we start from the CARA framework studied in Section 3.3.1, extended to allow for borrowing. Before analyzing the jointsearch problem, it is useful to recall here the solution to the single-agent problem.

Single-agent search problem. Let $a$ denote the asset position of the individual. Assets evolve according to the law of motion,

$$
\frac{d a}{d t}=r a+y-c
$$

where $r$ is the risk-free interest rate, $y$ is income (equal to $w$ during employment and $b$ during unemployment), and $c$ is consumption. The value functions for the employed and unemployed single agent are, respectively:

$$
\begin{aligned}
r W(w, a) & =\max _{c}\left\{u(c)+W_{a}(w, a)(r a+w-c)\right\} \\
r V(a) & =\max _{c}\left\{u(c)+V_{a}(a)(r a+b-c)\right\}+\alpha \int \max \{W(w, a)-V(a), 0\} d F(w),
\end{aligned}
$$

\footnotetext{
${ }^{17}$ This mechanism is closely related to Lise (2006), in which individuals climb the wage ladder but fall to the same unemployment benefit level upon layoff. As a result, in his model, the savings rate increases with the current wage level, whereas this increased precautionary savings demand manifests itself as delayed offer acceptance in our model.

${ }^{18}$ Some examples in which the decision maker is an individual are Costain (1999), Browning, Crossley, and Smith (2003), Lentz (2009), Lentz and Tranaes (2005), Rendon (2006), Lise (2006), Krusell et al. (2007), and Rudanko (2008).
} 
where the subscript denotes the partial derivative. These equations reflect the nonstationarity due to the change in assets over time. For example, the second term in the RHS of $(23)$ is $(d W / d t)=$ $(d W / d a) \cdot(d a / d t)$. And similarly for the second term in the RHS of $(24)$.

We begin by conjecturing that $r W(w, a)=u(r a+w)$. If this is the case, then the first-order condition (FOC) determining optimal consumption for the agent gives $u^{\prime}(c)=u(r a+w)$, which confirms the conjecture and establishes that the employed individual consumes his current wage plus the interest income on the risk-free asset. Let us now guess that $r V(a)=u\left(r a+w^{*}\right)$. Once gain, it is easy to verify this guess through the FOC of the unemployed agent. Substituting this solution back into equation (24) and using the CARA assumption yields

$$
w^{*}=b+\frac{\alpha}{\rho r} \int_{w^{*}}\left[u\left(w-w^{*}\right)-1\right] d F(w),
$$

which shows that $w^{*}$ is the reservation wage and is independent of wealth. Therefore, the unemployed worker consumes the reservation wage plus the interest income on his wealth. This result highlights an important point: the asset position of an unemployed worker deteriorates and, in presence of a debt constraint, she may hit it. As in the rest of the papers cited above which use this setup, we abstract from this possibility. The implicit assumption is that borrowing constraints are "loose," and by this we mean they do not bind along the solution for the unemployed agent.

Joint-search problem. When the couple searches jointly for jobs, the asset position of the couple still evolves based on (22), but now $y=2 b$ for the dual-searcher couple, $b+w_{1}$ for the worker-searcher couple, and $w_{1}+w_{2}$ for the employed couple. The value functions become

$$
\begin{aligned}
r T\left(w_{1}, w_{2}, a\right) & =\max _{c}\left\{u(c)+T_{a}\left(w_{1}, w_{2}, a\right)\left(r a+w_{1}+w_{2}-c\right)\right\} \\
r U(a) & =\max _{c}\left\{u(c)+U_{a}(a)(r a+2 b-c)\right\}+\alpha \int \max \{\Omega(w, a)-U(a), 0\} d F(w), \\
r \Omega\left(w_{1}, a\right) & =\max _{c}\left\{u(c)+\Omega_{a}\left(w_{1}, a\right)\left(r a+w_{1}+b-c\right)\right\} \\
& +\alpha \int \max \left\{T\left(w_{1}, w_{2}, a\right)-\Omega\left(w_{1}, a\right), \Omega\left(w_{2}, a\right)-\Omega\left(w_{1}, a\right), 0\right\} d F\left(w_{2}\right) .
\end{aligned}
$$

Solving this problem requires characterizing the optimal consumption policy for the dual-searcher couple $c_{u}(a)$, for the worker-searcher couple $c_{e u}\left(w_{1}, a\right)$, and for the dual-worker couple $c_{e}\left(w_{1}, w_{2}, a\right)$, as well as the reservation wage functions, now potentially a function of wealth too, which must satisfy, as usual: $\Omega\left(w^{* *}(a), a\right)=U(a), T\left(w_{1}, \phi\left(w_{1}, a\right), a\right)=\Omega\left(w_{1}, a\right)$, and $\Omega\left(\phi\left(w_{1}\right), a\right)=\Omega\left(w_{1}, a\right)$. The following proposition characterizes the solution to this problem.

Proposition 8 [CARA utility and access to financial markets] With CARA preferences, access to risk-free borrowing and lending, and "loose" debt constraints, the search behavior of a couple can be characterized as follows:

(i) The optimal consumption policies are: $c_{u}(a)=r a+2 w^{* *}, c_{e u}\left(w_{1}, a\right)=r a+w^{* *}+w_{1}$, and $c_{e}\left(w_{1}, w_{2}, a\right)=r a+w_{1}+w_{2}$. 
(ii) The reservation function $\phi$ of the worker-searcher couple is independent of $\left(w_{1}, a\right)$ and equals $w^{* *}$, so there is no breadwinner cycle.

(iii) The reservation wage $w^{* *}$ of the dual-searcher couple equals $w^{*}$, the reservation wage of the single-agent problem.

The main message of this proposition could perhaps be anticipated by the fact that borrowing effectively substitutes for the consumption smoothing provided within the household, making the latter redundant. Each spouse can implement search strategies that are independent from the other spouse's actions and, as a result, each acts as in the single-agent model. Of course, to the extent that borrowing constraints bind or preferences deviate from CARA, the equivalence result no longer applies.

The sharp contrast between the baseline model with no borrowing and this model with loose debt limits provides a useful guide for future empirical work. In particular, it suggests that deviations from single-agent search behavior in the data (such as the breadwinner cycle) are more likely to be detectable among young and poor households and may be less significant among older and wealthier households. Interestingly, we reached the same conclusion in Section 4.2, where we proved another "equivalence result" between single-agent and joint search in the presence of on-the-job search.

\subsection{Some illustrative simulations}

In this section, our goal is to gain some sense about the quantitative differences in labor market outcomes between the single-search and the joint-search economy. We start from the case of CRRA utility and exogenous separations. Later we add on-the-job search. Thus, the economy is characterized by the following set of parameters: $\left\{b, r, \rho, \delta, F, \alpha_{u}, \alpha_{e}\right\}$. When on-the-job search is not allowed, we simply set $\alpha_{e}=0$ and $\alpha \equiv \alpha_{u}$.

We first simulate labor market histories for a large number of individuals acting as singles, then compute their optimal choices and some key statistics: the reservation wage $w^{*}$, the mean wage, the unemployment rate, and unemployment duration. Second, we pair individuals together and treat them as couples solving the joint-search problem in exactly the same economy (i.e., same set of parameters). We use the same sequence of wage offers and separation shocks in both economies. The interest of the exercise lies in comparing the key labor market statistics across economies. For example, it is not obvious whether the joint-search model would have a higher or lower unemployment rate: for the dual-searcher couples, $w^{* *}<w^{*}$, but for the worker-searcher couple $\phi(w)$ is above $w^{*}$ at least for large enough wages of the employed spouse.

Calibration. We calibrate the model to replicate the salient features of the US economy. The time period in the model is set to one week of calendar time. The coefficient of relative risk aversion

$\rho$ will vary from zero (risk neutrality) up to eight in simulations. The weekly net interest rate, $r$, is set equal to 0.001 , corresponding to an annual interest rate of $5.3 \%$. Wage offers are drawn 
Table 1: Single versus Joint Search: CRRA Preferences

\begin{tabular}{lcccccccc}
\hline \hline & \multicolumn{2}{c}{$\rho=0$} & \multicolumn{2}{c}{$\rho=2$} & \multicolumn{2}{c}{$\rho=4$} & \multicolumn{2}{c}{$\rho=8$} \\
& Single & Joint & Single & Joint & Single & Joint & Single & Joint \\
\hline Res. wage $w^{*} / w^{* *}$ & 1.02 & 1.02 & 0.98 & 0.75 & 0.81 & 0.58 & 0.60 & 0.48 \\
Res. wage $\phi(1)$ & - & $n / a$ & - & 1.03 & - & 0.941 & - & 0.84 \\
Double ind. $\hat{w}$ & - & 1.02 & - & 1.02 & - & 0.94 & - & 0.82 \\
Mean wage & 1.06 & 1.06 & 1.07 & 1.10 & 1.01 & 1.05 & 1.001 & 1.01 \\
Mm ratio & 1.04 & 1.04 & 1.09 & 1.47 & 1.23 & 1.81 & 1.67 & 2.10 \\
Unemp. rate & $5.5 \%$ & $5.5 \%$ & $5.4 \%$ & $7.6 \%$ & $5.4 \%$ & $7.7 \%$ & $5.3 \%$ & $5.6 \%$ \\
Unemp. duration & 9.9 & 9.9 & 9.7 & 12.6 & 9.8 & 13.3 & 9.6 & 10 \\
$\quad$ Dual-searcher & - & 6 & - & 4.7 & - & 7.7 & - & 7.1 \\
$\quad$ Worker-searcher & - & 9.8 & - & 14.2 & - & 13.6 & - & 9.6 \\
Job quit rate & - & $0 \%$ & - & $11.1 \%$ & - & $5.55 \%$ & - & $0.74 \%$ \\
EQVAR- cons. & - & $0 \%$ & - & $4.5 \%$ & - & $14 \%$ & - & $26 \%$ \\
EQVAR- income & - & $0 \%$ & - & $1.1 \%$ & - & $2.8 \%$ & - & $0.7 \%$ \\
\hline
\end{tabular}

from a log-normal distribution with standard deviation $\sigma=0.1$ and mean $\mu=-\sigma^{2} / 2$ so that the average wage is always normalized to one. We set $\delta=0.0054$, which corresponds to a monthly employment-unemployment (exogenous) separation rate of 0.02 . For each risk aversion value, the offer arrival rate, $\alpha_{u}$, is recalibrated to generate an unemployment rate of roughly $0.055 .^{19}$ For the model with on-the-job search, we set the offer arrival rate on the job, $\alpha_{e}$, to match a monthly employment-employment transition rate of 0.02 . Finally, the value of leisure $b$ is set to 0.40 , i.e., $40 \%$ of the mean of the wage offer distribution.

Table 1 reports the results of our simulation. The first two columns confirm the statement in Proposition 1 that under risk neutrality the joint-search problem reduces to the single-search problem. Let us now consider the case with $\rho=2$. The reservation wage of the dual-searcher couple is almost $25 \%$ lower than in the single-search economy. And this is reflected in the much shorter unemployment durations of dual-searcher couples. At the same time, though, the reservation wage of worker-searcher couples is always higher than $w^{*}$. In the second row of the table, we report the reservation wage of the worker-searcher couple at the mean wage offer. Indeed, for these couples, unemployment duration is higher. Overall, this second effect dominates and the jointsearch economy displays a longer average unemployment duration-12.6 weeks instead of 9.7 - and a considerably higher unemployment rate, $7.6 \%$ instead of $5.4 \%$.

Comparing the mean wage tells a similar story. The job-search choosiness of worker-searcher

\footnotetext{
${ }^{19}$ As risk aversion goes up, $w^{* *}$ falls and unemployment duration decreases. So, to continue matching an unemployment rate of $5.5 \%$, we need to decrease the value of $\alpha_{u}$. For example, for $\rho=0, \alpha_{u}=0.4$ and for $\rho=8$, $\alpha_{u}=0.12$.
} 
couples dominates the insurance motive of dual-searcher couples, and the average wage is higher in the joint-search model. The ability of the couple to climb higher up the wage ladder is reflected in the endogenous quit rate (leading to the breadwinner cycle), which is sizeable, $11.1 \%$. Indeed, the region in which the breadwinner cycle is active is rather big, as measured by the gap between $w^{* *}$ and $\hat{w}$, which is equal to 2.7 times the standard deviation of the wage offer.

The next six columns in Table 1 display how these statistics change as we increase the coefficient of relative risk aversion. As is clear from the first row, in the case when $\rho=0$ the difference between $w^{*}$ and $w^{* *}$ is zero. As $\rho$ goes up, both reservation wages fall. Clearly, higher risk aversion implies a stronger demand for consumption smoothing, which makes the agent accept a job offer more quickly. However, the gap between $w^{*}$ and $w^{* *}$ first grows but then shrinks. Indeed, as $\rho \rightarrow \infty$, it must be true that $w^{*}=w^{* *}=b$, so the two economies converge again. As for $\phi(1)$, it falls as risk aversion increases, which means that for higher values of $\rho$, the worker-searcher couple accepts job offers more quickly, thus reducing unemployment. Indeed, at $\rho=8$ the unemployment rate and the mean wage are almost the same in the two economies.

We also report a measure of frictional wage dispersion, the mean-min ratio $(M m)$, defined as the ratio between the mean wage and the lowest wage, i.e., the reservation wage. Hornstein, Krusell, and Violante (2006) demonstrate that the sequential search model with homogeneous workers, when plausibly calibrated, generates very little frictional wage dispersion. The fifth row of Table 1 confirms this result. It also confirms the finding in Hornstein et al. that the $M m$ ratio increases with risk aversion. What is novel here is that the joint-search model generates more frictional dispersion: the reservation wage for the dual-searcher couple is lower, but the couple can climb the wage distribution faster which translates into a higher average wage.

Next, we discuss two separate measures of the welfare effects of joint search in the simulated economy. Recall that the jointly searching couple has two advantages: first, it can smooth consumption better, and second, it can get higher earnings. The first measure of welfare gain is the standard consumption-equivalent variation and embeds both advantages. The second is the change in lifetime income from being married, which isolates the second aspect - the novel one. ${ }^{20}$ The consumption-based measure of welfare gain is very large, not surprisingly. What is remarkable is that also the gains in terms of lifetime income can be very large - for example, around $2.8 \%$ for the case $\rho=4$. As risk aversion goes up, the welfare gains from family insurance keep increasing, but as explained above, the ones stemming from better search opportunities fade away.

Table 2 presents the results when on-the-job search is introduced into this environment. The first four columns simply confirm the theoretical results established in previous sections. For example, when agents are risk neutral, on-the-job search has no additional effect, and both the single- and joint-search problems yield the same solution regardless of parameter values. Similarly, as shown in Proposition 6 when on-the-job search is as effective as search during unemployment $\left(\alpha_{e}=\alpha_{u}\right)$,

\footnotetext{
${ }^{20}$ To make the welfare comparison between singles and couples meaningful, we assume that each spouse consumes half of the household's income (as opposed to "all income" assumed in the theoretical analysis). Notice that, with preferences used here, this alternative assumption does not affect any of our theoretical results.
} 
Table 2: Single versus Joint Search: CRRA Preferences and On-the-Job Search

\begin{tabular}{|c|c|c|c|c|c|c|c|c|}
\hline & \multicolumn{2}{|c|}{$\begin{array}{c}\rho=0 \\
\alpha_{u}=0.2, \alpha_{e}=0.03\end{array}$} & \multicolumn{2}{|c|}{$\begin{array}{c}\rho=2 \\
\alpha_{u}=0.1, \alpha_{e}=0.1\end{array}$} & \multicolumn{2}{|c|}{$\begin{array}{c}\rho=2 \\
\alpha_{u}=0.11, \alpha_{e}=0.02\end{array}$} & \multicolumn{2}{|c|}{$\begin{array}{c}\rho=4 \\
\alpha_{u}=0.11, \alpha_{e}=0.02\end{array}$} \\
\hline & Single & Joint & Single & Joint & Single & Joint & Single & Joint \\
\hline Res. wage $w^{*} / w^{* *}$ & 0.98 & 0.98 & 0.4 & 0.4 & 0.78 & 0.67 & 0.62 & 0.54 \\
\hline Res. wage $\phi(1)$ & - & 0.98 & - & 0.4 & - & 0.85 & - & 0.74 \\
\hline Double ind. $\hat{w}$ & - & 0.98 & - & 0.4 & - & 0.87 & - & 0.8 \\
\hline Mean wage & 1.13 & 1.13 & 1.16 & 1.16 & 1.08 & 1.09 & 1.08 & 1.09 \\
\hline Mm ratio & 1.15 & 1.15 & 2.90 & 2.90 & 1.38 & 1.63 & 1.74 & 2.02 \\
\hline Unemp. rate & $5.4 \%$ & $5.4 \%$ & $5.4 \%$ & $5.4 \%$ & $5.3 \%$ & $5.8 \%$ & $5.3 \%$ & $5.4 \%$ \\
\hline Unemp. duration & 9.8 & 9.8 & 10.5 & 10.5 & 9.7 & 10.6 & 9.6 & 9.8 \\
\hline Dual-searcher & - & 7 & - & 7.7 & - & 7.1 & - & 7 \\
\hline Worker-searcher & - & 9.4 & - & 9.9 & - & 10.2 & - & 9.3 \\
\hline EU quit rate & - & $0 \%$ & - & $0 \%$ & - & $0.93 \%$ & - & $0.19 \%$ \\
\hline EE transition & $0.45 \%$ & $0.45 \%$ & $1.03 \%$ & $1.03 \%$ & $0.49 \%$ & $0.47 \%$ & $0.51 \%$ & $0.49 \%$ \\
\hline EQVAR-cons. & - & $0 \%$ & - & $4.6 \%$ & - & $4.1 \%$ & - & $15 \%$ \\
\hline EQVAR-income & - & $0 \%$ & - & $0 \%$ & - & $0.2 \%$ & - & $0.05 \%$ \\
\hline
\end{tabular}

then, again, single and joint search coincide.

Overall, comparing these results to those in Table 1 shows that the effects of joint search on labor market outcomes are qualitatively the same as before, but they become much smaller quantitatively. This is perhaps not surprising in light of the discussion in Section 4, where we argued that joint search is a partial substitute for on-the-job search (or a costly version of it). Therefore, once on-thejob search is available, having a search partner is not so useful any longer to obtain higher earnings. But it obviously remains an effective means to smooth consumption, as evident from the last two lines of the table.

\section{$5 \quad$ Joint Search with Multiple Locations}

The importance of the geographical dimension of job search is undeniable. For the single-agent search problem, accepting a job in a different market could require a relocation cost that may be high enough to induce the agent to turn down the offer. In the joint-search problem, the spatial dimension introduces a new and interesting search friction. In addition to migration costs that also apply to a single agent, a couple is likely to suffer from the disutility of living apart if spouses accept jobs in different locations. This cost can easily rival or exceed the physical costs of relocation, since it is a flow cost as opposed to the latter, which are arguably better thought of as one-time costs.

To analyze the joint-search problem with multiple locations, we extend the framework proposed 
in Section 2 by introducing a fixed flow cost of living separately for a couple. As we shall see below, the introduction of location choice leads to several important changes in the search behavior of couples compared to a single agent, even with risk neutrality. For this reason, below we focus on the risk-neutral case. Furthermore, many of these changes are not favorable to couples, which serves to show that joint search can itself create new frictions. This is in contrast to the analysis performed so far, which only showed new opportunities of joint search. ${ }^{21}$

To keep the analysis tractable, we first consider agents that search for jobs in two symmetric locations and provide a theoretical characterization of the solution. In the next subsection, we examine the more general case with $L(>2)$ locations that is more suitable for a meaningful calibration and provide some results based on numerical simulations.

\subsection{Two locations}

Environment. A couple is an economic unit composed of a pair of risk-neutral spouses $(1,2)$. The economy has two locations. Couples incur a flow resource cost, denoted by $\kappa$, if the two spouses live apart. Denote by $i$ the "inside" location, i.e., the location where the couple resides, and by $o$ the "outside" location. Offers arrive at rate $\alpha_{i}$ from the current location and at rate $\alpha_{o}$ from the outside location, e.g., job search in the inside location is more effective. The two locations have the same wage offer distribution $F$. We assume away moving costs: the aim of the analysis is the comparison with the single-agent problem, and such costs would also be borne by the single agent.

A couple can be in one of four labor market states. First, if both spouses are unemployed and searching, they are referred to as a "dual-searcher couple." Second, if both spouses are employed in the same location (in which case they will stay in their jobs forever) we refer to them as a "dual-worker couple," but if they are employed in different locations we refer to them as a "separate dual-worker couple" (another absorbing state). Finally, if one spouse is employed and the other one is unemployed, we refer to them as a "worker-searcher couple." As explained, individuals in a dual-searcher couple have no advantage from living separately, so they will choose to live in the same location. Let $U, T\left(w_{1}, w_{2}\right), S\left(w_{1}, w_{2}\right)$, and $\Omega\left(w_{1}\right)$ be the value of these four states, respectively.

\footnotetext{
${ }^{21}$ This friction raises the issue of whether the couple should split. While the interaction between labor market frictions and changes in marital status is a fascinating question, it is beyond the scope of this paper. Here we assume that the couple has committed to stay together or, equivalently, that there is enough idiosyncratic nonmonetary value in the match to justify continuing the relationship.
} 
Then, we have

$$
\begin{aligned}
r T\left(w_{1}, w_{2}\right) & =w_{1}+w_{2} \\
r S\left(w_{1}, w_{2}\right) & =w_{1}+w_{2}-\kappa \\
r U & =2 b+2\left(\alpha_{i}+\alpha_{o}\right) \int \max \{\Omega(w)-U, 0\} d F(w) \\
r \Omega\left(w_{1}\right) & =w_{1}+b+\alpha_{i} \int \max \left\{T\left(w_{1}, w_{2}\right)-\Omega\left(w_{1}\right), \Omega\left(w_{2}\right)-\Omega\left(w_{1}\right), 0\right\} d F\left(w_{2}\right) \\
& +\alpha_{o} \int \max \left\{S\left(w_{1}, w_{2}\right)-\Omega\left(w_{1}\right), \Omega\left(w_{2}\right)-\Omega\left(w_{1}\right), 0\right\} d F\left(w_{2}\right) .
\end{aligned}
$$

The first three value functions are easily understood and do not require explanation. The value function for a worker-searcher couple now has to account separately for inside and outside offers. If an inside offer arrives, the choice is the same as in the one-location case, since no cost of living separately is incurred. If, however, an outside offer is received, the unemployed spouse may turn down the offer or may accept the job, in which case the couple has two options: either it chooses to live separately incurring cost $\kappa$, or the employed spouse quits and follows the newly employed spouse to the new location to avoid the cost.

The decision of the dual-searcher couple is entirely characterized by the reservation wage $w^{* *}$. For the worker-searcher couple, let $\phi_{i}\left(w_{1}\right)$ and $\phi_{o}\left(w_{1}\right)$ be the reservation functions corresponding to inside and outside offers. Once again, these functions are piecewise with one piece corresponding to the 45-degree line. By inspecting equation (32), it is immediate that, as in the one-location case, $\phi_{i}^{-1}\left(w_{1}\right)$ and $\phi_{o}^{-1}\left(w_{1}\right)$ characterize the quitting decision.

Single-agent search. Before proceeding further, it is straightforward to see that the singlesearch problem with two locations is the same as the one-location case, with the appropriate modification to the reservation wage to account for separate arrival rates from two locations. In the risk-neutral case, we have

$$
w^{*}=b+\frac{\alpha_{i}+\alpha_{o}}{r} \int_{w^{*}}[1-F(w)] d w .
$$

Recall that in the one-location case, risk neutrality resulted in an equivalence between the singlesearch and joint-search problems. As the next proposition shows, this result does not hold in the two-location case anymore, as long as there is a positive cost $\kappa$ of living apart:

Proposition 9 [Two locations] With risk neutrality, two locations, and $\kappa>0$, the search behavior of a couple can be characterized as follows. There is a wage value

$$
\hat{w}_{S}=b+\kappa+\frac{\alpha_{i}}{r} \int_{\hat{w}_{S}-\kappa}[1-F(w)] d w+\frac{\alpha_{o}}{r} \int_{\hat{w}_{S}}[1-F(w)] d w
$$

and a corresponding value $\hat{w}_{T}=\hat{w}_{S}-\kappa$ such that:

(i) $w^{* *} \in\left(\hat{w}_{T}, \hat{w}\right)$, whereas $w^{*} \in\left(\hat{w}, \hat{w}_{S}\right)$. Therefore, $w^{* *}<w^{*}$, which implies that the breadwinner cycle exists. 
Figure 6: Reservation Wage Functions for Outside Offers in Two-Location Model

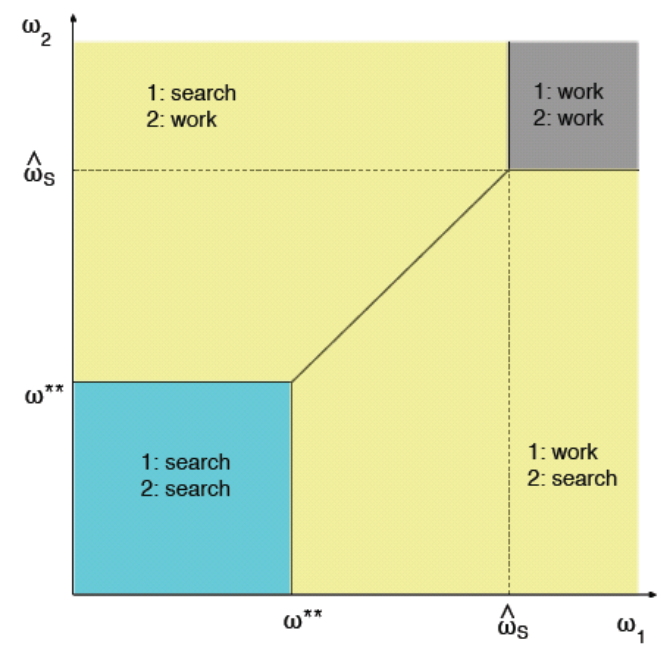

(ii) For outside offers, the reservation wage function of a worker-searcher couple has the following properties: for $w_{1}<\hat{w}_{S}, \phi_{o}\left(w_{1}\right)=w_{1}$, and for $w_{1} \geq \hat{w}_{S}, \phi_{o}\left(w_{1}\right)=\hat{w}_{S}$.

(iii) For inside offers, the reservation wage function of a worker-searcher couple has the following properties: for $w_{1}<\hat{w}, \phi_{i}\left(w_{1}\right)=w_{1}$, for $w_{1} \in\left[\hat{w}, \hat{w}_{S}\right), \phi_{i}\left(w_{1}\right)$ is strictly decreasing and for $w_{1} \geq \hat{w}_{S}, \phi_{i}\left(w_{1}\right)=\hat{w}_{T}$.

The first useful result is that the dual-searcher couple is less choosy than the individual agent because it is effectively facing a worse job offer distribution: some wage offer configurations are attainable only in different locations, hence by paying the cost of living apart.

Figures 6 and 7 graphically show the reservation wage functions for outside offers and inside offers, respectively. As seen in these figures, the reservation wage functions for both inside and outside offers are quite different from the corresponding ones of the model with one location (Figure 1). In particular, the reservation wage functions for both inside offers and outside offers now depend on the wage of the employed spouse at least when $w_{1} \in\left(w^{* *}, \hat{w}_{S}\right)$. This has several implications.

Consider first outside offers for a worker-searcher couple where one spouse is employed at $w_{1}<$ $\hat{w}_{S}$ (Figure 6). The couple will reject wage offers below $w_{1}$, but when faced with a wage offer above $w_{1}$, the employed worker will quit his job and follow the other spouse to the outside location. The $\operatorname{cost} \kappa$ is too large to justify living apart while being employed at such wages. In this region, the breadwinner cycle is active "across locations." In contrast, when $w_{1}>\hat{w}_{S}$ if the couple receives a wage offer $w_{2}>\hat{w}_{S}$, it will bear the cost of living separately in order to receive such high wages.

Comparing Figure 7 for inside offers to Figure 6, it is immediate that the range of wages for which inside offers are accepted by a worker-searcher couple is larger, since no cost $\kappa$ has to be paid. Interestingly, the reservation function $\phi_{i}\left(w_{1}\right)$ now has three distinct pieces. For $w_{1}$ large enough, it is constant, as in the single-agent case. In the intermediate range $\left(\hat{w}, \hat{w}_{S}\right)$ the function is decreasing. 
Figure 7: Reservation Wage Functions for Inside Offers in Two-Location Model

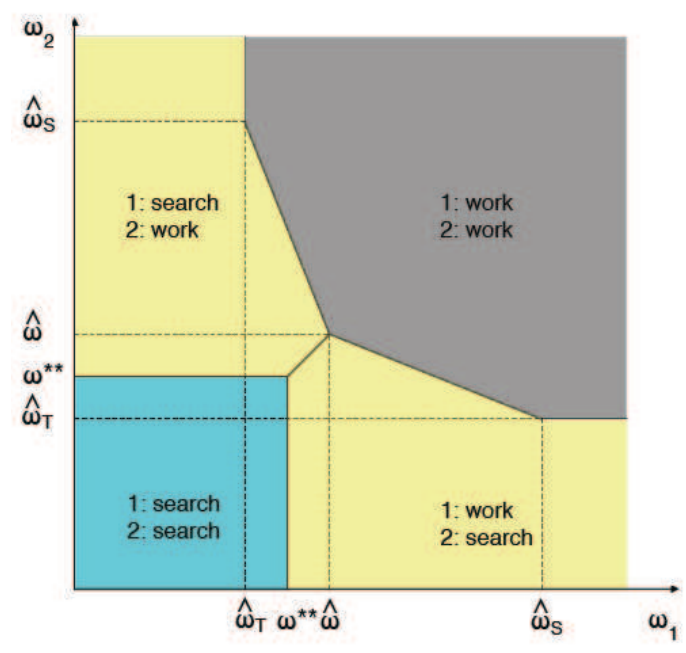

This phenomenon is linked to the reservation function for outside offers $\phi_{o}$, which is increasing in this range: as $w_{1}$ rises the gains from search coming from outside offers are lower (it takes a very high outside wage offer $w_{2}$ to induce the employed spouse to quit), hence the reservation wage for inside offers falls.

For $w_{1}$ small enough, the reservation function $\phi_{i}\left(w_{1}\right)$ is increasing and equal to the wage of the employed spouse. In this region, the breadwinner cycle is again active, so whenever the wage offer is higher than the employed spouse's wage but smaller than $\varphi_{i}\left(w_{1}\right)$, the couple goes through the breadwinner cycle. However, if the wage offer is high enough, the potential negative impact of the outside wage offers induces the couple to become a dual-worker couple. Using the same reasoning we applied to the range $\left(\hat{w}, \hat{w}_{S}\right)$, the reservation wage for being a dual-worker couple decreases as $w_{1}$ increases.

In this multiple location model, we obtained two results that were also present in our previous environment with one location and risk-aversion: (i) the couple being less picky than the individual, and (ii) the breadwinner cycle. As explained, the analogy stops here, since the economic intuition is completely different in the two models.

Tied-movers and tied-stayers. In a seminal paper, Mincer (1978) has studied empirically the job-related migration decisions of couples in the United States (during the 1960s and 1970s). Following the terminology introduced by Mincer, we refer to a spouse who rejects an outside offer that she would accept when single as a "tied-stayer." Similarly, we refer to a spouse who follows her spouse to the new destination even though her individual calculus dictates otherwise as a "tiedmover." Using data from the 1962 Bureau of Labor Statistics (BLS) survey of unemployed persons, Mincer estimated that " 22 percent or two-thirds of the wives of moving families would be tiedmovers, while 23 percent out of 70 percent of wives in families of stayers declared themselves to be 
Figure 8: Tied-Stayers and Tied-Movers in the Joint-Search Model

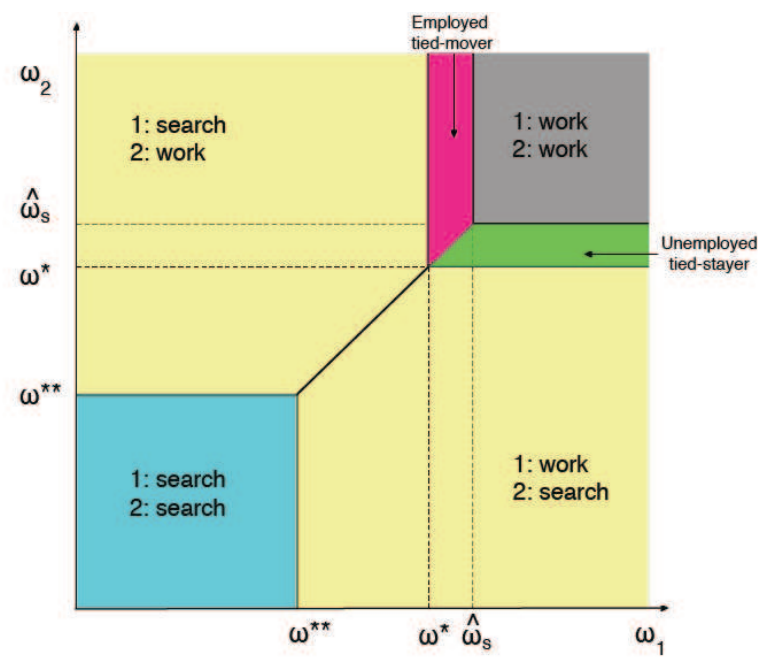

tied-stayers" (page 758). ${ }^{22}$

Figure 8 re-draws the reservation wage functions for outside offers and indicates the regions that give rise to tied-stayers and tied-movers in our model. First, if the wage of the employed spouse, $w_{1}$, is higher than $w^{*}$, then the unemployed spouse rejects outside offers and stays in the current location for all wage offers less than $\phi_{i}\left(w_{1}\right)$. In contrast, a single agent would accept all offers $w_{2}$ above $w^{*}$, which is less than $\phi_{i}\left(w_{1}\right)$ by Proposition 9 . Therefore, an unemployed spouse who rejects an outside wage offer $w_{2} \in\left(w^{*}, \phi_{i}\left(w_{1}\right)\right)$ is formally a tied-stayer (as shown in Figure 8).

There is a region in which the employed spouse is a tied-mover. Suppose the wage of the employed spouse, $w_{1}$, is between $w^{*}$ and $\hat{w}_{S}$, and the unemployed spouse receives an outside wage offer higher than $w_{1}$, then the unemployed spouse accepts the offer, the employed spouse quits the job, and both move to the other location. The employed spouse would not move to the other location if she were single, since she would not be searching any longer, so the employed spouse is a tied-mover (see Figure 8).

Both sets of choices involve potentially large concessions by each spouse compared to the situation where he/she were single, but they are optimal from a joint decision perspective. This opens the possibility of the welfare costs of being in a couple versus being single with respect to job search, an aspect of the model which we analyze quantitatively, through simulation, in the next section.

\footnotetext{
${ }^{22}$ More precisely, Mincer (1978) defines an individual to be a tied-stayer (a tied-mover) if the individual cites his/her spouse's job as the main reason for turning down (accepting) a job from a different location: Mincer wrote (page 758): "The unemployed were asked whether they would accept a job in another area comparable with the one they lost. A positive answer was given by 30 percent of the married men, 21 percent of the single women, and only 8 percent of the married women. Most people who said no cited family, home, and relatives as reasons for the reluctance to move. However, one quarter of the women singled out their husbands' job in the present area as the major deterrent factor."
} 
Table 3: Single versus Joint Search: Nine Locations and Risk-Neutral Preferences

\begin{tabular}{lcccc}
\hline \hline & \multicolumn{2}{c}{$\kappa=0$} & $\kappa=0.1$ & $\kappa=0.3$ \\
& Single & Joint & Joint & Joint \\
\hline$w^{*} / w^{* *}$ (Reservation wage) & 1.02 & 1.02 & 0.97 & 0.94 \\
$\hat{w}_{T}$ & - & 1.02 & 0.95 & 0.88 \\
$\hat{w}$ (Double indiff. point) & - & 1.02 & 0.99 & 0.97 \\
$\hat{w}_{S}$ & - & 1.02 & 1.04 & 1.13 \\
$\phi_{i}(1)$ (Reservation wage) & - & $n / a$ & 0.984 & 0.95 \\
Mean wage & 1.058 & 1.058 & 1.06 & 1.045 \\
Mm ratio & 1.04 & 1.04 & 1.09 & 1.11 \\
Unemployment rate & $5.5 \%$ & $5.5 \%$ & $6.9 \%$ & $13.7 \%$ \\
Unemployment duration & 9.9 & 9.9 & 9.8 & 13.0 \\
$\quad$ Dual-searcher & - & 6.5 & 3.3 & 3.0 \\
$\quad$ Worker-searcher & - & 9.3 & 12.9 & 28.0 \\
Movers (\% of population) & $0.52 \%$ & $0.52 \%$ & $0.74 \%$ & $1.26 \%$ \\
Stayers (\% of population) & $1.12 \%$ & $1.12 \%$ & $1.53 \%$ & $3.4 \%$ \\
Tied-movers/Movers & - & $0 \%$ & $29 \%$ & $56 \%$ \\
Tied-stayer/Stayers & - & $0 \%$ & $11 \%$ & $23 \%$ \\
Job quit rate & - & $0 \%$ & $23 \%$ & $50 \%$ \\
EQVAR-income & - & $0 \%$ & $-0.8 \%$ & $-6.5 \%$ \\
\hline
\end{tabular}

\subsection{Some illustrative simulations with multiple locations}

The two-location case serves as a convenient benchmark that illustrates all the key mechanisms. For the simulation exercise, we extend the framework described above to multiple locations and allow exogenous separations. Specifically, consider an economy with $L$ geographically separate symmetric labor markets. Firms in each location generate offers at flow rate $\psi$. A fraction $\theta$ of both types of offers are distributed equally to the $L-1$ outside locations and the remaining $(1-\theta)$ is made to the local market. ${ }^{23}$ The value functions corresponding to this economy are provided in Appendix B and are straightforward extensions of the value functions in (29)-(32).

The number of locations, $L$, is set to nine representing the number of US census divisions and $\theta$ is set to $1-1 / L$, implying that firms make offers to all locations with equal probability. The remaining parameters are calibrated as before, i.e., to match certain labor market statistics in the single-agent version of the model.

\footnotetext{
${ }^{23}$ The assumption that there are a very large number of individuals in each location, combined with the fact that the environment is stationary (i.e., no location-specific shocks) implies that we can take the number of workers in each location as constant, despite the fact that workers are free to move across locations and across employment states depending on the offers they receive.
} 
Table 3 presents the simulation results. A comparison of the first two columns confirms that the single- and joint-search problems are equivalent when there is no disutility from living apart $(\kappa=0)$. The third and fourth columns show the results when $\kappa=0.1$ and $\kappa=0.3$, respectively - representing a flow cost equal to $10 \%$ and $30 \%$ of the mean offered wage. First, the reservation wages are in line with our theoretical results in Proposition 9: $\hat{w}_{T}<w^{* *}<w^{*}<\hat{w}_{S}$. Second, the presence of the cost $\kappa$ makes outside offers less appealing, making the couple reject some offers that a single person would accept. As a result, the average wage is lower and the unemployment rate is higher in the joint-search economy. In fact, when $\kappa=0.3$ the unemployment rate is substantially higher $-13.7 \%$ compared to $5.5 \%$ in the single-agent model. However, the average duration of unemployment is not necessarily longer under joint search: when $\kappa=0.1$ the average duration falls to 9.8 weeks from 9.9 weeks in the single agent case, but rises to 13 weeks when $\kappa$ is further raised to 0.3. The next two rows decompose average unemployment duration into the component experienced by dual-searcher couples and by worker-searcher couples. The duration of the former group is shorter than that of single agents (since $w^{* *}<w^{*}$ ) and gets even shorter as $\kappa$ increases (falls from 6.5 weeks to 3 weeks in column 4). However, because worker-searcher couples face a smaller number of feasible job offers from outside locations, they have much longer unemployment spells: 12.9 weeks when $\kappa=0.1$ and 28 weeks when $\kappa=0.3$, compared to 9.3 weeks when $\kappa=0$. Overall, there are more people who are unemployed at any point in time, and some of these unemployed workers - those in worker-searcher families - stay unemployed for much longer than they would have had they been single, while trying to resolve their joint-location problem.

We next turn to the impact of joint search on the migration decision of couples. In our context, we define a couple to be a "mover" if at least one spouse moves for job-related reasons. This includes dual-searcher couples who move to another location because one of the spouses accepts an outside job offer, and worker-searcher couples if at least one spouse moves to another location because the unemployed spouse accepts an offer at another location. ${ }^{24}$ Similarly, we define a couple to be a "stayer"if either member of the couple turns down an outside job offer.

Using this definition, the fraction of movers in the population is $0.52 \%$ per week when $\kappa=0$; it rises to $0.74 \%$ when $\kappa=0.1$ and to $1.26 \%$ when $\kappa=0.3$. Part of the rise in the moving rate is mechanically related to the rise in the unemployment rate with $\kappa$ : because there is no on-thejob search, individuals only get job offers when they are unemployed, which in turn increases the number of individuals who accept offers and move. Notice also that while the fraction of movers appears high in all three cases, this is not surprising given that we are completely abstracting from the physical costs of moving. Perhaps more striking is the fact that almost $56 \%$ of all movers are tied-movers when $\kappa=0.3$, using the definition in Mincer (1978) described above. The fraction of tied-stayers is also sizeable: $21 \%$ in the high-friction case. The voluntary quit rate - which is defined as the fraction of employment-to-unemployment transitions that are due to voluntary quits - is as

\footnotetext{
${ }^{24}$ However, consider a dual-worker couple in which spouses live in separate locations. If one of the spouses receives a separation shock and becomes unemployed, she will move to her spouse's location. In this case, the household is not considered to be a mover, since the move did not occur in order to accept a job.
} 
high as $50 \%$ when $\kappa=0.3$.

Finally, a comparison of lifetime wage incomes shows that the friction introduced by jointlocation search can be substantial: it reduces the lifetime income of a couple by about $0.8 \%$ (per person) compared to a single agent when $\kappa=0.1$ and by $6.5 \%$ when $\kappa=0.3$. Overall, these results show that with multiple locations, joint-search behavior can deviate substantially from the standard single-agent search.

\section{Conclusions}

From a theoretical viewpoint, there are additional forces that could influence joint-search decisions in the labor market, beyond those studied in this paper. Some examples include complementarity/substitutability of leisure between spouses (Burdett and Mortensen, 1977), or consumptionsharing rules that deviate from full income pooling, as in the collective model (Chiappori, 1992), or the option given to the couple to split and break up the marriage (Aiyagari, Greenwood, and Guner, 2000). A search-based analysis of labor and marriage market dynamics with general preferences, multiple locations, and more sophisticated models for within-household consumption distribution is an ambitious research project. Gemici (2008) represents a significant step in this direction.

The qualitative properties of the joint-search problem established here provide guidance on conducting quantitative analyses more effectively. Clearly, quantitative studies require richer models where proving general results is extremely challenging. However, knowing the properties of the reservation wage functions in special cases (like ours) is useful in guessing the numerical solution or in interpreting simulation-based results. Moreover, the qualitatively different behaviors implied by different subclasses of HARA preferences caution against using linear-quadratic approximations to CRRA utility functions often made in computational analysis.

A particularly fruitful extension of the framework studied in this paper would be to introduce asymmetries between spouses (in terms of skills, job opportunities, or comparative advantage in home production) or between locations (in terms of the size and diversity of the local labor market). For example, small differences in the mean or variance of the wage offer distribution between men and women could be amplified through joint search and generate a large observed gender wage gap. Such an extension would provide a natural framework to think about "leading" and "trailing" spouses in couples, which has been the focus of much empirical research on family labor supply and migration patterns since the seminal work by Mincer (1978).

Similarly, with multiple locations, larger cities could command a premium by offering a more diverse set of job opportunities, thereby mitigating the frictions associated with joint search. Consistent with this view, Costa and Kahn (2000) document that, since the 1960s, dual-career couples have increasingly relocated to large metropolitan areas in the United States (more so than comparable singles). The same period has also witnessed a housing price boom, which has been especially pronounced in large metropolitan areas, and it would be interesting to examine if the rise in the number of dual-career couples and their migration to larger cities have been a quantitatively important 
contributor to this trend.

The model studied in Section 5 generalized to allow asymmetry in skills across spouses, asymmetry in locations, on-the-job search, and access to financial markets can be brought to the data and estimated structurally. It not only could be used to quantify the cost of living separately for couples, but also could be used to shed light on the quantitative importance of joint search for a host of empirical issues, and for the design of unemployment insurance and other labor market policies. The challenge is to access micro data with household-level information on the detailed labor market histories of both members of the couple and on their geographical movements. A more feasible task is the structural estimation of a search model to understand patterns of multiple job holding, an environment that we showed to be isomorphic to joint search, under some assumptions. The survey data needed for such task are more readily available.

Finally, there is a growing literature on the design of unemployment insurance policies in search models where individual workers can self-insure through savings (Lentz, 2009; Shimer and Werning 2008). Joint search is both an additional channel of household consumption smoothing and a vehicle to select better jobs. Since generous unemployment insurance is often advocated on the basis of these two considerations (e.g., Acemoglu and Shimer, 1999), recognizing that job search is often joint might limit the scope for copious unemployment benefits. 


\section{A Proofs}

Proof. [Lemma 1] Rewrite equation (6) using equation (4):

$$
r \Omega(w)=u(w+b)+\alpha g(w)
$$

where

$$
g(w) \equiv \int \max \left\{\frac{u\left(w+w_{2}\right)}{r}, \Omega\left(w_{2}\right)-\Omega(w), 0\right\} d F\left(w_{2}\right) .
$$

We construct the proof by contradiction. Let us assume $\Omega^{\prime}(w) \leq 0$. From equation $(34), r \Omega^{\prime}(w)-$ $u^{\prime}(w+b)=\alpha g^{\prime}(w)$. Then, $g^{\prime}(w) \leq \frac{-u^{\prime}(w+b)}{\alpha}<0$. If $\Omega$ is a decreasing function, then $\Omega\left(w_{2}\right)-\Omega(w)$ is an increasing function of $w$. This means that all the terms inside the max operator of the $g$ function are increasing, which implies that $g$ is an increasing function, i.e., $g^{\prime}(w) \geq 0$, for each $w$, which is a contradiction. Thus, $\Omega^{\prime}(w)>0$.

Proof. [Proposition 1] From the definition of the worker-searcher reservation wage when the quit option is not exercised, the couple has to be indifferent between both partners being employed and only one being employed. This means that $\phi$ has to satisfy: $\Omega\left(w_{1}\right)=T\left(w_{1}, \phi\left(w_{1}\right)\right)$. We conjecture that the quitting option is never exercised. This allows us to disregard the second term inside the max operator in (6). Using this last equality, equations (6) and (4), and the fact that workers are risk neutral, the equation characterizing $\phi\left(w_{1}\right)$ becomes

$$
\phi\left(w_{1}\right)=b+\frac{\alpha}{r} \int_{\phi\left(w_{1}\right)}\left[w_{2}-\phi\left(w_{1}\right)\right] d F\left(w_{2}\right) .
$$

It is clear that $\phi\left(w_{1}\right)$ does not depend on $w_{1}$, and the above equation is exactly equation (3) of the single-search problem. So, $\phi\left(w_{1}\right)=w^{*}=\hat{w}$. As a result, $\phi^{-1}\left(w_{1}\right)=\infty$, confirming the guess that the employed spouse never quits, since quits occur only if the wage offer $w_{2}$ exceeds $\phi^{-1}\left(w_{1}\right)$.

Now we will establish that $w^{* *}=w^{*}$. Equation (7) implies that

$$
r \Omega\left(w^{* *}\right)=r U=2 b+\frac{2 \alpha}{r} \int_{w^{* *}} r \Omega^{\prime}(w)[1-F(w)] d w .
$$

At $w_{1}=w^{*}$, we can rewrite equation (6) in the following way:

$$
r \Omega\left(w^{*}\right)=w^{*}+b+\frac{\alpha}{r} \int_{w^{*}} r \Omega^{\prime}(w)[1-F(w)] d w .
$$

Subtracting (35) from (36) multiplied by 2 and using the fact that $r \Omega\left(w^{*}\right)=2 w^{*}$ yields

$$
r\left[\Omega\left(w^{*}\right)-\Omega\left(w^{* *}\right)\right]=\frac{2 \alpha}{r} \int_{w^{*}}^{w^{* *}} r \Omega^{\prime}(w)[1-F(w)] d w .
$$

Since $\Omega$ is strictly increasing, $w^{*} \geq w^{* *}$ implies $\Omega\left(w^{*}\right) \geq \Omega\left(w^{* *}\right)$, but then the above equation in turn implies that $w^{* *}=w^{*}$. Thus, the quit option will never be exercised.

Proof. [Proposition 2] It is useful to begin by first proving part (ii) of the proposition. At the reservation wage for the worker-searcher couple we have $T\left(w_{1}, \phi\left(w_{1}\right)\right)=\Omega\left(w_{1}\right)$. Let us begin by 
conjecturing that there is a value for $w_{1}$ above which the employed spouse never quits his job. Therefore, in this range we do not have to worry about the second argument of the max operator in (6). Using equations (6) and (4), we get

$$
\begin{aligned}
u\left(w_{1}+\phi\left(w_{1}\right)\right)-u\left(w_{1}+b\right) & =\frac{\alpha}{r} \int_{\phi\left(w_{1}\right)}\left[T\left(w_{1}, w_{2}\right)-\Omega\left(w_{1}\right)\right] d F\left(w_{2}\right) \\
& =\frac{\alpha}{r} \int_{\phi\left(w_{1}\right)}\left[u\left(w_{1}+w_{2}\right)-u\left(w_{1}+\phi\left(w_{1}\right)\right)\right] d F\left(w_{2}\right) \\
-\rho u\left(w_{1}\right)\left(u\left(\phi\left(w_{1}\right)\right)-u(b)\right) & =-\rho u\left(w_{1}\right) \frac{\alpha}{r} \int_{\phi\left(w_{1}\right)}\left[u\left(w_{2}\right)-u\left(\phi\left(w_{1}\right)\right)\right] d F\left(w_{2}\right) \\
u\left(\phi\left(w_{1}\right)\right)-u(b) & =\frac{\alpha}{r} \int_{\phi\left(w_{1}\right)}\left[u\left(w_{2}\right)-u\left(\phi\left(w_{1}\right)\right)\right] d F\left(w_{2}\right),
\end{aligned}
$$

where the second line uses the definition of $\phi$ and the third line uses the CARA assumption $u\left(c_{1}+c_{2}\right)=-\rho u\left(c_{1}\right) u\left(c_{2}\right)$. Note that this is exactly the same equation characterizing the reservation wage of the single unemployed (equation (3)). So, we can conclude that in this region $\phi\left(w_{1}\right)=w^{*}$. Moreover, $\hat{w}$ is a singleton since $\phi$ crosses the 45-degree line only once, so $\hat{w}=w^{*}$. If $w_{1} \geq w^{*}$, the employed spouse does not quit the job, since $\phi^{-1}\left(w_{1}\right)=\infty$ and quits take place if $w_{2}>\phi^{-1}\left(w_{1}\right)$, which confirms the initial guess.

Now that we have characterized the part of the $\phi$ function for $w_{1} \geq w^{*}$, we turn to the part below $w^{*}$. Here we have $\phi\left(w_{1}\right)=w_{1}$, and quits are possible as long as $w^{* *}<w^{*}$ as stated in part (i). This is what we prove next. When the wage of the employed agent is equal the double indifference point $\hat{w}$, we have $r \Omega(\hat{w})=u(2 \hat{w})$ from (10). Subtracting (5) from this equation, we get

$$
r\left[\Omega(\hat{w})-\Omega\left(w^{* *}\right)\right]=u(2 \hat{w})-u(2 b)-2 \alpha \int_{w^{* *}}\left[\Omega(w)-\Omega\left(w^{* *}\right)\right] d F(w) .
$$

Evaluate equation (6) at $\hat{w}$, and note that $T(\hat{w}, w)=\Omega(w)$ to arrive at

$$
u(2 \hat{w})=u(\hat{w}+b)+\alpha \int_{\hat{w}}[\Omega(w)-\Omega(\hat{w})] d F(w) .
$$

Combining these two equations yields

$$
\begin{aligned}
r\left[\Omega(\hat{w})-\Omega\left(w^{* *}\right)\right] & =2 u(\hat{w}+b)-u(2 \hat{w})-u(2 b)-2 \alpha \int_{w^{* *}}^{\hat{w}} \Omega^{\prime}(w)[1-F(w)] d w \\
& =\rho[-2 u(\hat{w}) u(b)+u(\hat{w}) u(\hat{w})+u(b) u(b)]-2 \alpha \int_{w^{* *}}^{\hat{w}} \Omega^{\prime}(w)[1-F(w)] d w \\
& =\rho[u(\hat{w})-u(b)]^{2}-2 \alpha \int_{w^{* *}}^{\hat{w}} \Omega^{\prime}(w)[1-F(w)] d w,
\end{aligned}
$$

where the second line again uses the CARA assumption. Suppose now, ad absurdum, that $w^{* *} \geq \hat{w}$, then clearly, $L H S \leq 0$. But since obviously $\hat{w}>b$, and $2 \alpha \int_{w^{* *}}^{\hat{w}} \Omega^{\prime}(w)(1-F(w)) d w \leq 0$, we have that $R H S>0$, a contradiction. Thus, $w^{* *}<\hat{w}=w^{*}$.

Proof. [Proposition 3] We begin with part (ii). The proof proceeds by conjecturing that there is a value $w_{1}$ above which the employed spouse never quits his job and showing that this leads to 
a contradiction. For a quit not to occur beyond a wage threshold, we need to have $\phi^{\prime} \leq 0$ in that region since $\phi^{-1}$ would also be decreasing in this case. Indeed, suppose that the couple draws a wage $w_{2}>\phi\left(w_{1}\right)$. The reservation wage of the employed spouse upon quitting would be $\phi^{-1}\left(w_{2}\right)<w_{1}$, where $w_{1}$ is the current wage, which would not justify quitting. Then, the equation characterizing $\phi\left(w_{1}\right)$ becomes, as usual,

$$
u\left(w_{1}+\phi\left(w_{1}\right)\right)-u\left(w_{1}+b\right)=\frac{\alpha}{r} \int_{\phi\left(w_{1}\right)}\left[u\left(w_{1}+w_{2}\right)-u\left(w_{1}+\phi\left(w_{1}\right)\right)\right] d F\left(w_{2}\right) .
$$

Consider a wage level $\tilde{w}_{1}>w_{1}$. Then, rearranging, we get

$$
\begin{aligned}
1 & =\frac{\alpha}{r} \int_{\phi\left(w_{1}\right)}\left[\frac{u\left(w_{1}+w_{2}\right)-u\left(w_{1}+\phi\left(w_{1}\right)\right)}{u\left(w_{1}+\phi\left(w_{1}\right)\right)-u\left(w_{1}+b\right)}\right] d F\left(w_{2}\right) \\
& \leq \frac{\alpha}{r} \int_{\phi\left(\tilde{w}_{1}\right)}\left[\frac{u\left(w_{1}+w_{2}\right)-u\left(w_{1}+\phi\left(\tilde{w}_{1}\right)\right)}{u\left(w_{1}+\phi\left(\tilde{w}_{1}\right)\right)-u\left(w_{1}+b\right)}\right] d F\left(w_{2}\right) \\
& <\frac{\alpha}{r} \int_{\phi\left(\tilde{w}_{1}\right)}\left[\frac{u\left(\tilde{w}_{1}+w_{2}\right)-u\left(\tilde{w}_{1}+\phi\left(\tilde{w}_{1}\right)\right)}{u\left(\tilde{w}_{1}+\phi\left(\tilde{w}_{1}\right)\right)-u\left(\tilde{w}_{1}+b\right)}\right] d F\left(w_{2}\right) \\
& =1,
\end{aligned}
$$

which is a contradiction. The first weak inequality comes from the fact that $\phi^{\prime} \leq 0$. The second strict inequality holds because of the DARA utility assumption (Pratt, 1964, Theorem 1): if $u$ is in the DARA class, for any $k>0$ and $m, n, p, q$ such that $p<q \leq m<n$, we have

$$
\frac{u(n)-u(m)}{u(q)-u(p)}<\frac{u(n+k)-u(m+k)}{u(q+k)-u(p+k)} .
$$

Here $p=w_{1}+b, q=m=w_{1}+\phi\left(\tilde{w}_{1}\right), n=w_{1}+w_{2}$ and $k=\tilde{w}_{1}-w_{1}$.

The contradiction shows that the conjecture $\phi^{\prime} \leq 0$ is not correct. Therefore, $\phi\left(w_{1}\right)$ must be strictly increasing in $w_{1}$ over this range. In this case, the employed spouse may find it optimal to quit the job if the unemployed receives a sufficiently high wage offer, i.e., whenever $w_{2}>\phi^{-1}\left(w_{1}\right)$. This leads us to another conjecture: for any $w_{1}<\hat{w}, \phi\left(w_{1}\right)=w_{1}$ and for $w_{1} \geq \hat{w}, 0<\phi^{\prime}<1$. Then, the equation characterizing $\phi\left(w_{1}\right)$ becomes

$$
\begin{aligned}
1 & =\frac{\alpha}{r} \int_{\phi\left(w_{1}\right)}^{\phi^{-1}\left(w_{1}\right)}\left[\frac{u\left(w_{1}+w_{2}\right)-u\left(w_{1}+\phi\left(w_{1}\right)\right)}{u\left(w_{1}+\phi\left(w_{1}\right)\right)-u\left(w_{1}+b\right)}\right] d F\left(w_{2}\right) \\
& +\frac{\alpha}{r} \int_{\phi^{-1}\left(w_{1}\right)}\left[\frac{r \Omega\left(w_{2}\right)-u\left(w_{1}+\phi\left(w_{1}\right)\right)}{u\left(w_{1}+\phi\left(w_{1}\right)\right)-u\left(w_{1}+b\right)}\right] d F\left(w_{2}\right) .
\end{aligned}
$$

This conjecture implies that for any $w_{1}, \Omega\left(w_{2}\right)>T\left(w_{1}, w_{2}\right)=u\left(w_{1}+w_{2}\right)$ for all $w_{2}>\phi^{-1}\left(w_{1}\right)$. So, for any $w_{1}$, we can find an $\varepsilon>0$, sufficiently small, such that $\int_{\phi^{-1}\left(w_{1}\right)} r \Omega\left(w_{2}\right) d F\left(w_{2}\right) \geq$ $\int_{\phi^{-1}\left(w_{1}\right)} u\left(w_{1}+w_{2}+\varepsilon\right) d F\left(w_{2}\right)$. Then, for such an $\varepsilon>0$, using the DARA property in equation 
(37), we get

$$
\begin{aligned}
1= & \frac{\alpha}{r} \int_{\phi\left(w_{1}\right)}^{\phi^{-1}\left(w_{1}\right)}\left[\frac{u\left(w_{1}+w_{2}\right)-u\left(w_{1}+\phi\left(w_{1}\right)\right)}{u\left(w_{1}+\phi\left(w_{1}\right)\right)-u\left(w_{1}+b\right)}\right] d F\left(w_{2}\right) \\
& +\frac{\alpha}{r} \int_{\phi^{-1}\left(w_{1}\right)}\left[\frac{r \Omega\left(w_{2}\right)-u\left(w_{1}+\phi\left(w_{1}\right)\right)}{u\left(w_{1}+\phi\left(w_{1}\right)\right)-u\left(w_{1}+b\right)}\right] d F\left(w_{2}\right) \\
< & \frac{\alpha}{r} \int_{\phi\left(w_{1}\right)}^{\phi^{-1}\left(w_{1}\right)}\left[\frac{u\left(w_{1}+w_{2}+\varepsilon\right)-u\left(w_{1}+\varepsilon+\phi\left(w_{1}\right)\right)}{u\left(w_{1}+\phi\left(w_{1}\right)+\varepsilon\right)-u\left(w_{1}+b+\varepsilon\right)}\right] d F\left(w_{2}\right) \\
& +\frac{\alpha}{r} \int_{\phi^{-1}\left(w_{1}\right)}\left[\frac{r \Omega\left(w_{2}\right)-u\left(w_{1}+\phi\left(w_{1}\right)+\varepsilon\right)}{u\left(w_{1}+\phi\left(w_{1}\right)+\varepsilon\right)-u\left(w_{1}+b+\varepsilon\right)}\right] d F\left(w_{2}\right) .
\end{aligned}
$$

Moreover, since

$$
\begin{aligned}
1 & =\frac{\alpha}{r} \int_{\phi\left(w_{1}+\varepsilon\right)}^{\phi^{-1}\left(w_{1}+\varepsilon\right)}\left[\frac{u\left(w_{1}+w_{2}+\varepsilon\right)-u\left(w_{1}+\phi\left(w_{1}+\varepsilon\right)+\varepsilon\right)}{u\left(w_{1}+\varepsilon+\phi\left(w_{1}+\varepsilon\right)\right)-u\left(w_{1}+b+\varepsilon\right)}\right] d F\left(w_{2}\right) \\
& +\frac{\alpha}{r} \int_{\phi^{-1}\left(w_{1}+\varepsilon\right)}\left[\frac{r \Omega\left(w_{2}\right)-u\left(w_{1}+\phi\left(w_{1}+\varepsilon\right)+\varepsilon\right)}{u\left(w_{1}+\phi\left(w_{1}+\varepsilon\right)+\varepsilon\right)-u\left(w_{1}+b+\varepsilon\right)}\right] d F\left(w_{2}\right),
\end{aligned}
$$

then $\phi\left(w_{1}\right)<\phi\left(w_{1}+\varepsilon\right)$ for $\varepsilon>0$ sufficiently small, implying $\phi^{\prime}>0$.

We now prove part (i) of the proposition. We first show that $w^{* *}<\hat{w}$. Subtracting equation (5) from equation (10), we obtain

$$
r\left[\Omega(\hat{w})-\Omega\left(w^{* *}\right)\right]=u(2 \hat{w})-u(2 b)-2 \alpha \int_{w^{* *}}\left[\Omega(w)-\Omega\left(w^{* *}\right)\right] d F(w) .
$$

At $w_{1}=\hat{w}$, we can write equation (6) as

$$
r \Omega(\hat{w})=u(\hat{w}+b)+\alpha \int_{\hat{w}}[\Omega(w)-\Omega(\hat{w})] d F(w)
$$

because for any wage offer $w_{2}>\hat{w}$, the unemployed accepts the offer and the employed quits the job, meaning $\Omega\left(w_{2}\right)>T\left(\hat{w}, w_{2}\right)$. Multiplying the above equation by 2 and using equation (10), we arrive at

$$
u(2 \hat{w})=2 u(\hat{w}+b)-u(2 \hat{w})+2 \alpha \int_{\hat{w}}[\Omega(w)-\Omega(\hat{w})] d F\left(w_{2}\right) .
$$

Substituting this expression for $u(2 \hat{w})$ into the RHS of equation (38) delivers

$$
\begin{aligned}
r\left[\Omega(\hat{w})-\Omega\left(w^{* *}\right)\right] & =2 u(\hat{w}+b)-u(2 \hat{w})-u(2 b) \\
& +2 \alpha\left[\int_{\hat{w}}[\Omega(w)-\Omega(\hat{w})] d F(w)-\int_{w^{* *}}\left[\Omega(w)-\Omega\left(w^{* *}\right)\right] d F(w)\right] \\
& =2 u(\hat{w}+b)-u(2 \hat{w})-u(2 b)+2 \alpha \int_{\hat{w}}^{w^{* *}} \Omega^{\prime}(w)[1-F(w)] d w,
\end{aligned}
$$

where the second line uses integration by parts. Now, by concavity of $u, 2 u(\hat{w}+b)-u(2 \hat{w})-u(2 b)>$ 0 . Suppose, ad absurdum, $w^{* *} \geq \hat{w}$. Then, the RHS of the above equation is strictly positive, but the LHS is either negative or zero, which is a contradiction. Therefore, $w^{* *}<\hat{w}$. 
We now prove, by contradiction, that $\hat{w}>w^{*}$. Suppose that $w^{*} \geq \hat{w}$. Recall that equation (6) evaluated at $\hat{w}$ can be written as

$$
r \Omega(\hat{w})=u(\hat{w}+b)+\alpha \int_{\hat{w}}[\Omega(w)-\Omega(\hat{w})] d F(w) .
$$

Since $r \Omega(\hat{w})=u(2 \hat{w})$, we can rewrite the above relationship as

$$
\begin{aligned}
u(2 \hat{w})-u(\hat{w}+b) & =\frac{\alpha}{r} \int_{\hat{w}}[r \Omega(w)-u(2 \hat{w})] d F(w) \\
& >\frac{\alpha}{r} \int_{\hat{w}}[r T(\hat{w}, w)-u(2 \hat{w})] d F(w) \\
& =\int_{\hat{w}}[u(\hat{w}+w)-u(\hat{w}+\hat{w})] d F(w) .
\end{aligned}
$$

Rearrange the above equation and, once again, use the property of DARA utility to get

$$
\begin{aligned}
1 & >\frac{\alpha}{r} \int_{\hat{w}}\left[\frac{u(\hat{w}+w)-u(\hat{w}+\hat{w})}{u(\hat{w}+\hat{w})-u(\hat{w}+b)}\right] d F(w) \\
& >\frac{\alpha}{r} \int_{\hat{w}}\left[\frac{u(w)-u(\hat{w})}{u(\hat{w})-u(b)}\right] d F(w) \\
& \geq \frac{\alpha}{r} \int_{w^{*}}\left[\frac{u(w)-u\left(w^{*}\right)}{u\left(w^{*}\right)-u(b)}\right] d F(w) \\
& =1 .
\end{aligned}
$$

The second inequality is due to the property of DARA utility, and the third weak inequality derives from the assumption $w^{*} \geq \hat{w}$ and from $u$ being an increasing function. The last equality comes from the definition of the reservation wage for the single agent. Since we reached a contradiction, it must be that $\hat{w}>w^{*}$.

Finally, we need to prove that $\phi^{\prime}<1$. Let us assume $\phi^{\prime}>1$. This means that for $w_{1}>\hat{w}$, $\phi\left(w_{1}\right)>\phi^{-1}\left(w_{1}\right)=\varphi\left(w_{1}\right)$. For any $w_{1}>\hat{w}$, if the wage offer $w_{2}>\phi\left(w_{1}\right)$, the unemployed accepts the offer, meaning $T\left(w_{1}, w_{2}\right)>\Omega\left(w_{1}\right)$. But since $w_{2}>\phi\left(w_{1}\right)>\phi^{-1}\left(w_{1}\right)$, the employed quits the job at the same time, which means $\Omega\left(w_{2}\right)>T\left(w_{1}, w_{2}\right)>\Omega\left(w_{1}\right)$. With the same logic, one can see that if $w_{2} \in\left(w_{1}, \phi\left(w_{1}\right)\right)$, we get $\Omega\left(w_{2}\right)>\Omega\left(w_{1}\right)>T\left(w_{1}, w_{2}\right)$. If $w_{2} \in\left(\varphi\left(w_{1}\right), w_{1}\right)$, we have $\Omega\left(w_{1}\right)>\Omega\left(w_{2}\right)>T\left(w_{1}, w_{2}\right)$ and if $w_{2}<\varphi\left(w_{1}\right)$, we have $\Omega\left(w_{1}\right)>T\left(w_{1}, w_{2}\right)>\Omega\left(w_{2}\right)$. Hence, if $w_{2}>w_{1}$, then the unemployed accepts the job and the employed quits the job, forcing the reservation wage to be $w_{1}$. Hence, $\phi\left(w_{1}\right)=w_{1}$, resulting in $\phi^{\prime}=1$, a contradiction. We can also rule out the case where $\phi^{\prime}=1$, where no household would become a dual-worker couple, by showing that for a sufficiently large wage offer, dual employment is optimal.

Proof. [Proposition 5] There are three cases to consider.

( $i$ ) Consider a dual-searcher couple. Recall that by definition of $w^{* *}, U=\Omega\left(w^{* *}\right)>T\left(2 w^{* *}\right)>$ $T\left(z+w^{*}\right)>T(z+w)$ for all $w<w^{* *}$. Hence, no wage offer below $w^{* *}$ is accepted by the searching couple, since dual search always dominates. For wage offers above $w^{* *}, T(z, w)<T\left(w^{* *}, w\right)<$ $\Omega(w)$ since under CARA or DARA $\phi$ is a nondecreasing function. Therefore, a dual-searcher couple 
that samples an offer above $w^{* *}$ becomes a worker-searcher couple. Simple inspection of equation (18) shows that the worker-searcher couple will never transit through nonparticipation. It remains to be proved that being a dual nonparticipant couple is also dominated. This is straightforward, since $U=\Omega\left(w^{* *}\right)>T\left(2 w^{* *}\right)>T(2 z)$. Dual search dominates dual nonparticipation. Hence, nonparticipation never occurs.

(ii) Since $U=\Omega\left(w^{* *}\right)<\Omega(z)$, search-nonparticipation is always preferred to dual search. Since we are in the range $z<\hat{w}$, where quitting is optimal, we know that $\phi(z)=z$. As soon as the searcher receives a job offer higher $w$ than $z$, she becomes employed and the couple becomes a worker-searcher couple. From that point onward, the dynamics are as in the baseline model.

(iii) Under this configuration, $U=\Omega\left(w^{* *}\right)<\Omega(\hat{w})<\Omega(z)$, which proves that search- nonparticipation is always preferred to dual search. However, we can write $\Omega(z)=T(z, \phi(z))<T(2 z)$, since above $\hat{w}$ we have $\phi(z) \leq z$. Thus, both members enter the nonparticipation pool, which is an absorbing state.

Proof. [Proposition 6] Let us conjecture that $\phi\left(w_{1}\right)=w^{* *}$ for any value of $w_{1}$, i.e., $T\left(w^{* *}, w_{2}\right)=$ $\Omega\left(w_{2}\right)$. This implies that the quit option is never exercised, since any observed $w_{1}$ will be greater than or equal to $w^{* *}$. So, one can disregard the second argument in the max operator in (20). Evaluating $(20)$ at $w^{* *}$ yields

$$
r \Omega\left(w^{* *}\right)=u\left(w^{* *}+b\right)+2 \alpha_{u} \int \max \left\{\Omega(w)-\Omega\left(w^{* *}\right), 0\right\} d F(w) d F\left(w_{2}\right),
$$

where we have used the fact that $\alpha_{e}=\alpha_{u}$ and the conjecture. Since $\Omega\left(w^{* *}\right)=U$, comparing the above equation to (19) yields that $w^{* *}=b$. We now verify our conjecture. From (21) evaluated at $w_{2}=w^{* *}:$

$$
\begin{aligned}
r T\left(w_{1}, w^{* *}\right) & =u\left(w_{1}+b\right)+\alpha_{e} \int \max \left\{T\left(w_{1}^{\prime}, w^{* *}\right)-T\left(w_{1}, w^{* *}\right), 0\right\} d F\left(w_{1}^{\prime}\right) \\
& +\alpha_{u} \int \max \left\{T\left(w_{1}, w_{2}^{\prime}\right)-T\left(w_{1}, w^{* *}\right), 0\right\} d F\left(w_{2}^{\prime}\right) \\
& =u\left(w_{1}+b\right)+\alpha_{e} \int \max \left\{\Omega\left(w_{1}^{\prime}\right)-\Omega\left(w_{1}\right), 0\right\} d F\left(w_{1}^{\prime}\right) \\
& +\alpha_{u} \int \max \left\{T\left(w_{1}, w_{2}^{\prime}\right)-\Omega\left(w_{1}\right), 0\right\} d F\left(w_{2}^{\prime}\right) \\
& =\Omega\left(w_{1}\right),
\end{aligned}
$$

which confirms our conjecture, since $T\left(w^{* *}, w_{2}\right)=\Omega\left(w_{2}\right)$ implies that $\phi\left(w_{2}\right)=w^{* *}$. Finally, from equation $(21)$, it is immediate that $\eta\left(w_{i}\right)=w_{i}$, which completes the proof.

Proof. [Proposition 7] We begin with part (ii). The value functions (4) and (6) modified to allow 
for exogenous separations are

$$
\begin{aligned}
(r+2 \delta) T\left(w_{1}, w_{2}\right) & =u\left(w_{1}+w_{2}\right)+\delta\left[\Omega\left(w_{1}\right)+\Omega\left(w_{2}\right)\right] \\
r \Omega\left(w_{1}\right) & =u\left(w_{1}+b\right)-\delta\left[\Omega\left(w_{1}\right)-U\right] \\
& +\alpha \int \max \left\{T\left(w_{1}, w_{2}\right)-\Omega\left(w_{1}\right), \Omega\left(w_{2}\right)-\Omega\left(w_{1}\right), 0\right\} d F\left(w_{2}\right) .
\end{aligned}
$$

From the definition of reservation function $\phi$ for the worker-searcher couple, $T\left(w_{1}+\phi\left(w_{1}\right)\right)=$ $\Omega\left(w_{1}\right)$, we have:

$$
u\left(w_{1}+\phi\left(w_{1}\right)\right)-\delta\left[\Omega\left(w_{1}\right)-\Omega\left(\phi\left(w_{1}\right)\right)\right]=r \Omega\left(w_{1}\right) .
$$

Let us assume that there is a wage value $w_{1}$ beyond which the employed worker never quits. Then, in this range $\phi\left(w_{1}\right)$ is a nonincreasing function. Using this property in (40) and substituting into the above equation, we get

$$
\begin{aligned}
u\left(w_{1}+\phi\left(w_{1}\right)\right) & =u\left(w_{1}+b\right)+\alpha \int_{\phi\left(w_{1}\right)}\left[T\left(w_{1}, w_{2}\right)-T\left(w_{1}, \phi\left(w_{1}\right)\right)\right] d F\left(w_{2}\right)-\delta\left[\Omega\left(\phi\left(w_{1}\right)\right)-U\right] \\
& =u\left(w_{1}+b\right)+h\left(\phi\left(w_{1}\right)\right) \\
& +\frac{\alpha}{r+2 \delta} \int_{\phi\left(w_{1}\right)}\left[u\left(w_{1}+w_{2}\right)-u\left(w_{1}+\phi\left(w_{1}\right)\right)\right] d F\left(w_{2}\right)
\end{aligned}
$$

where

$$
h(x)=\frac{\alpha \delta}{r+2 \delta} \int_{x}\left[\Omega\left(w_{2}\right)-\Omega(x)\right] d F\left(w_{2}\right)-\delta[\Omega(x)-U]
$$

with $h$ decreasing in $x$. Rearrange equation (41) as

$$
1=\frac{\alpha}{r+2 \delta} \int_{\phi\left(w_{1}\right)}\left[\frac{u\left(w_{1}+w_{2}\right)-u\left(w_{1}+\phi\left(w_{1}\right)\right)}{u\left(w_{1}+\phi\left(w_{1}\right)\right)-u\left(w_{1}+b\right)}\right] d F\left(w_{2}\right)+\frac{h\left(\phi\left(w_{1}\right)\right)}{u\left(w_{1}+\phi\left(w_{1}\right)\right)-u\left(w_{1}+b\right)} .
$$

Since $\phi\left(w_{1}\right)$ is a decreasing function of $w_{1}$, then, for any $\tilde{w}_{1}>w_{1}$, we have

$0 \leq \frac{u\left(w_{1}+w_{2}\right)-u\left(w_{1}+\phi\left(w_{1}\right)\right)}{u\left(w_{1}+\phi\left(w_{1}\right)\right)-u\left(w_{1}+b\right)} \leq \frac{u\left(\tilde{w}_{1}+w_{2}\right)-u\left(\tilde{w}_{1}+\phi\left(w_{1}\right)\right)}{u\left(\tilde{w}_{1}+\phi\left(w_{1}\right)\right)-u\left(\tilde{w}_{1}+b\right)} \leq \frac{u\left(\tilde{w}_{1}+w_{2}\right)-u\left(\tilde{w}_{1}+\phi\left(\tilde{w}_{1}\right)\right)}{u\left(\tilde{w}_{1}+\phi\left(\tilde{w}_{1}\right)\right)-u\left(\tilde{w}_{1}+b\right)}$,

where the first weak inequality stems from the fact that $u$ is CARA or DARA, and the second from the fact that $\phi$ is weakly decreasing. Overall, the above condition implies the first term in equation (42) is an increasing function of $w_{1}$.

Since $h$ is decreasing in $x$, and $\phi\left(\tilde{w}_{1}\right) \leq \phi\left(w_{1}\right)$ for $\tilde{w}_{1}>w_{1}$, we have

$$
\frac{h\left(\phi\left(w_{1}\right)\right)}{u\left(w_{1}+\phi\left(w_{1}\right)\right)-u\left(w_{1}+b\right)}<\frac{h\left(\phi\left(\tilde{w}_{1}\right)\right)}{u\left(\tilde{w}_{1}+\phi\left(\tilde{w}_{1}\right)\right)-u\left(\tilde{w}_{1}+b\right)},
$$

because the right hand side has a weakly greater numerator and a strictly smaller denominator than the left-hand side. And we reach the following contradiction:

$$
\begin{aligned}
1 & =\frac{\alpha}{r+2 \delta} \int_{\phi\left(w_{1}\right)}\left[\frac{u\left(w_{1}+w_{2}\right)-u\left(w_{1}+\phi\left(w_{1}\right)\right)}{u\left(w_{1}+\phi\left(w_{1}\right)\right)-u\left(w_{1}+b\right)}\right] d F\left(w_{2}\right)+\frac{h\left(\phi\left(w_{1}\right)\right)}{u\left(w_{1}+\phi\left(w_{1}\right)\right)-u\left(w_{1}+b\right)} \\
& <\frac{\alpha}{r+2 \delta} \int_{\phi\left(\tilde{w}_{1}\right)}\left[\frac{u\left(\tilde{w}_{1}+w_{2}\right)-u\left(\tilde{w}_{1}+\phi\left(\tilde{w}_{1}\right)\right)}{u\left(\tilde{w}_{1}+\phi\left(\tilde{w}_{1}\right)\right)-u\left(\tilde{w}_{1}+b\right)}\right] d F\left(w_{2}\right)+\frac{h\left(\phi\left(\tilde{w}_{1}\right)\right)}{u\left(\tilde{w}_{1}+\phi\left(\tilde{w}_{1}\right)\right)-u\left(\tilde{w}_{1}+b\right)} \\
& =1 .
\end{aligned}
$$


We conclude that $\phi\left(w_{1}\right)$ is strictly increasing in $w_{1}$. Once we have established this result, similar arguments used in the proof of Proposition 3 apply here for part (i) to complete the proof.

Proof. [Proposition 8] We conjecture that $r T\left(w_{1}, w_{2}, a\right)=u\left(r a+w_{1}+w_{2}\right)$. Then the RHS of equation (26) becomes

$$
\max _{c}\left\{u(c)+u^{\prime}\left(r a+w_{1}+w_{2}\right)\left(r a+w_{1}+w_{2}-c\right)\right\} .
$$

The FOC implies $u^{\prime}(c)=u^{\prime}\left(r a+w_{1}+w_{2}\right)$, so $c_{e}\left(a, w_{1}, w_{2}\right)=r a+w_{1}+w_{2}$. If we plug this optimal consumption function back into equation (26), we arrive at $r T\left(w_{1}, w_{2}, a\right)=\left(r a+w_{1}+w_{2}\right)$, which confirms the conjecture.

Similarly, let us guess that $r \Omega\left(w_{1}, a\right)=u\left(r a+w_{1}+\phi\left(w_{1}\right)\right)$. Again, plugging this guess into the RHS of equation (28), the FOC implies $c_{e u}\left(w_{1}, a\right)=r a+w_{1}+\phi\left(w_{1}, a\right)$. Substituting this function back into (28) gives

$$
\begin{aligned}
& r \Omega\left(w_{1}, a\right)=u\left(r a+w_{1}+\phi\left(w_{1}, a\right)\right)+u^{\prime}\left(r a+w_{1}+\phi\left(w_{1}, a\right)\right)\left(b-\phi\left(w_{1}, a\right)\right) \\
&+ \frac{\alpha}{r} \int \max \left\{u\left(r a+w_{1}+w_{2}\right)-u\left(r a+w_{1}+\phi\left(w_{1}, a\right)\right),\right. \\
&\left.u\left(r a+w_{2}+\phi\left(w_{1}, a\right)\right)-u\left(r a+w_{1}+\phi\left(w_{1}, a\right)\right), 0\right\} d F\left(w_{2}\right) .
\end{aligned}
$$

Using the CARA property of $u$, we can simplify the RHS and rewrite the above equation as

$$
\begin{aligned}
r \Omega\left(w_{1}, a\right)= & u\left(r a+w_{1}+\phi\left(w_{1}, a\right)\right)\left[1-\rho\left(b-\phi\left(w_{1}, a\right)\right)\right. \\
& \left.-\frac{\alpha}{r} \int \max \left\{u\left(w_{2}-\phi\left(w_{1}, a\right)\right)-1, u\left(w_{2}-w_{1}\right)-1,0\right\} d F\left(w_{2}\right)\right] .
\end{aligned}
$$

Now, using the definition of $\phi$ and the expression for $r T\left(w_{1}, \phi\left(w_{1}, a\right), a\right)$ in the above equation, we have

$$
\phi\left(w_{1}, a\right)=b+\frac{\alpha}{\rho r} \int\left[u\left(\max \left\{w_{2}-\phi\left(w_{1}, a\right), w_{2}-w_{1}, 0\right\}\right)-1\right] d F\left(w_{2}\right) .
$$

As in the CARA case without saving, conjecture that there is a value $w_{1}$ such that beyond that value the quitting option is never exercised. Then, in this range we can ignore from the second argument in the max operator and rewrite

$$
\phi\left(w_{1}, a\right)=b+\frac{\alpha}{\rho r} \int_{\phi\left(w_{1}, a\right)}\left[u\left(w_{2}-\phi\left(w_{1}, a\right)\right)-1\right] d F\left(w_{2}\right),
$$

which implies that $\phi$ is a constant function, independent of $\left(w_{1}, a\right)$. Moreover, comparing (43) to the equivalent equation for the single-agent problem (25) yields that $\phi\left(w_{1}, a\right)=w^{*}$.

Finally, let us turn to $U$ and conjecture that $r U(a)=u\left(r a+2 w^{* *}\right)$. Substituting this guess into equation (27) and taking the FOC leads to the optimal policy function $c_{u}(a)=r a+2 w^{* *}$, which confirms the guess. Then, using the CARA assumption, equation (27) becomes

$$
\begin{aligned}
r U(a) & =u\left(r a+2 w^{* *}\right)-\rho u\left(r a+2 w^{* *}\right)\left(2 b-2 w^{* *}\right)-\frac{2 \alpha}{r} u\left(r a+2 w^{* *}\right) \int_{w^{* *}}\left[u\left(w-w^{* *}\right)-1\right] d F(w) \\
& =u\left(r a+2 w^{* *}\right)\left[1-\rho\left(2 b-2 w^{* *}\right)-\frac{2 a}{r} \int_{w^{* *}}\left[u\left(w-w^{* *}\right)-1\right] d F(w)\right]
\end{aligned}
$$


and using $r U(a)=u\left(r a+2 w^{* *}\right)$ we arrive at

$$
w^{* *}=b+\frac{a}{\rho r} \int_{w^{* *}}\left[u\left(w-w^{* *}\right)-1\right] d F(w),
$$

which, once again, compared to (25) implies that $w^{* *}=w^{*}$. This concludes the proof.

Proof. [Proposition 9] We first prove parts (ii) and (iii), which establish the behavior of the reservation wage functions. The reservation function for an outside offer satisfies $S\left(w_{1}, \phi_{o}\left(w_{1}\right)\right)=$ $\Omega\left(w_{1}\right)$. As before, we begin by conjecturing that the quit option is never exercised beyond a certain wage threshold. In this range, from the definition of $\phi_{o}\left(w_{1}\right)$ :

$$
\begin{aligned}
\phi_{o}\left(w_{1}\right) & =b+\kappa+\alpha_{i} \int_{\phi_{i}\left(w_{1}\right)}\left[T\left(w_{1}, w_{2}\right)-\Omega\left(w_{1}\right)\right] d F\left(w_{2}\right)+\alpha_{o} \int_{\phi_{o}\left(w_{1}\right)}\left[S\left(w_{1}, w_{2}\right)-\Omega\left(w_{1}\right)\right] d F\left(w_{2}\right) \\
& =b+\kappa+\alpha_{i} \int_{\phi_{i}\left(w_{1}\right)} T_{2}\left(w_{1}, w_{2}\right)\left(1-F\left(w_{2}\right)\right) d w_{2}+\alpha_{o} \int_{\phi_{o}\left(w_{1}\right)} S_{2}\left(w_{1}, w_{2}\right)\left(1-F\left(w_{2}\right)\right) d w_{2} \\
& =b+\kappa+\frac{\alpha_{i}}{r} \int_{\phi_{i}\left(w_{1}\right)}\left[1-F\left(w_{2}\right)\right] d w_{2}+\frac{\alpha_{o}}{r} \int_{\phi_{o}\left(w_{1}\right)}\left[1-F\left(w_{2}\right)\right] d w_{2}
\end{aligned}
$$

where the second line is obtained through integration by parts and the third line uses the risk neutrality assumption, which assures $T_{2}\left(w_{1}, w_{2}\right)=S_{2}\left(w_{1}, w_{2}\right)=\frac{1}{r}$.

We now turn to inside offers. The reservation function for an inside offer satisfies $T\left(w_{1}, \phi_{i}\left(w_{1}\right)\right)=$ $\Omega\left(w_{1}\right)$. We keep analyzing the region of $w_{1}$ above $\hat{w}_{S}$ where we know the employed worker does not quit upon receiving outside offers. From the definition of $\phi_{i}\left(w_{1}\right)$ :

$$
\begin{aligned}
\phi_{i}\left(w_{1}\right) & =b+\alpha_{i} \int_{\phi_{i}\left(w_{1}\right)}\left[T\left(w_{1}, w_{2}\right)-\Omega\left(w_{1}\right)\right] d F\left(w_{2}\right)+\alpha_{o} \int_{\phi_{o}\left(w_{1}\right)}\left[S\left(w_{1}, w_{2}\right)-\Omega\left(w_{1}\right)\right] d F\left(w_{2}\right) \\
& =b+\frac{\alpha_{i}}{r} \int_{\phi_{i}\left(w_{1}\right)}\left[1-F\left(w_{2}\right)\right] d w_{2}+\frac{\alpha_{o}}{r} \int_{\phi_{o}\left(w_{1}\right)}\left[1-F\left(w_{2}\right)\right] d w_{2}
\end{aligned}
$$

where the second line is derived exactly as for the outside offer case.

Combining equations (44) and (45), we can verify that $\phi_{o}\left(w_{1}\right)$ and $\phi_{i}\left(w_{1}\right)$ are independent of $w_{1}$, and $\phi_{i}\left(w_{1}\right)=\phi_{o}\left(w_{1}\right)-\kappa$ for $w_{1} \geq \hat{w}_{S}$. This confirms the conjecture and yields $\hat{w}_{T}=\hat{w}_{S}-\kappa$.

Let us extend our analysis of inside offers to the region in which $w_{1}$ is lower than $\hat{w}_{S}$. Here, the reservation function $\phi_{i}$ satisfies

$$
\phi_{i}\left(w_{1}\right)=b+\frac{\alpha_{i}}{r} \int_{\phi_{i}\left(w_{1}\right)}[1-F(w)] d w+\frac{\alpha_{o}}{r} \int_{w_{1}}^{\hat{w}_{S}} \Omega^{\prime}\left(w_{2}\right)\left[1-F\left(w_{2}\right)\right] d w_{2},
$$

since the employed worker will quit upon receiving outside offers. Clearly, $\phi_{i}\left(w_{1}\right)$ is decreasing in $w_{1}$ over this region. We conclude that for $w_{1} \geq \hat{w}_{S}$, we have $\phi_{i}\left(w_{1}\right)=\hat{w}_{T}$ and in the range $\left[\hat{w}, \hat{w}_{S}\right)$ the function $\phi_{i}$ is decreasing, with $\hat{w}$ denoting the double indifference point, i.e., the intersection with the 45-degree line. As usual, below $\hat{w}, \phi_{i}\left(w_{1}\right)=w_{1}$. This completes the proof of parts (ii) and (iii).

We next prove part (i) of the proposition: $w^{* *} \in\left(\hat{w}_{T}, \hat{w}\right)$ and $w^{*} \in\left(\hat{w}, \hat{w}_{S}\right)$, so $w^{* *}<w^{*}$. It is also useful to recall that $\hat{w}_{T}<\hat{w}<\hat{w}_{S}$. 
Step 1: We first show $w^{* *} \in\left(\hat{w}_{T}, \hat{w}\right)$. Equation (32) evaluated at the point $w_{1}=\hat{w}_{T}$ becomes

$$
r \Omega\left(\hat{w}_{T}\right)=\hat{w}_{T}+b+\left(\alpha_{i}+\alpha_{o}\right) \int_{\hat{w}_{T}} \Omega^{\prime}(w)[1-F(w)] d w .
$$

The reservation wage of the dual-searcher couple $w^{* *}$ is characterized by the equation

$$
r \Omega\left(w^{* *}\right)=2 b+2\left(\alpha_{i}+\alpha_{o}\right) \int_{w^{* *}} \Omega^{\prime}(w)(1-F(w)) d w .
$$

Now subtract equation (46) multiplied by 2 from equation (47) and get

$$
r\left[\Omega\left(w^{* *}\right)-\Omega\left(\hat{w}_{T}\right)\right]=r \Omega\left(\hat{w}_{T}\right)-2 \hat{w}_{T}+2\left(\alpha_{i}+\alpha_{o}\right) \int_{w^{* *}}^{\hat{w}_{T}} \Omega^{\prime}(w)[1-F(w)] d w .
$$

Suppose $w^{* *} \leq \hat{w}_{T}$, then the LHS of the above equation is negative or zero. The second term of the RHS is positive. The term $r \Omega\left(\hat{w}_{T}\right)-2 \hat{w}_{T}$ is also positive because for $w_{1}=\hat{w}_{T}$, the employed worker would prefer to quit his job rather than remain employed (more precisely, he strictly prefers it for an outside offer, but he is indifferent for an inside offer). Therefore the RHS is positive, which is a contradiction. So $w^{* *}>\hat{w}_{T}$.

Step 2: Similarly, consider equation (32) evaluated at $w_{1}=\hat{w}$. Note that at $w_{1}=\hat{w}$, for inside offers the employed spouse never exercises the quit option, whereas for outside offers, she does. So, equation (32) evaluated at $w_{1}=\hat{w}$ becomes

$$
r \Omega(\hat{w})=\hat{w}+b+\frac{\alpha_{i}}{r} \int_{\hat{w}}[1-F(w)] d w+\frac{\alpha_{o}}{r} \int_{\hat{w}} r \Omega^{\prime}(w)[1-F(w)] d w .
$$

Also note that since $\hat{w}$ is the double indifference point for inside offers, $r \Omega(\hat{w})=2 \hat{w}$. Again, subtract this last equation multiplied by 2 from equation (47) to get

$r\left[\Omega\left(w^{* *}\right)-\Omega(\hat{w})\right]=\frac{2 \alpha_{i}}{r}\left[\int_{w^{* *}} r \Omega^{\prime}(w)[1-F(w)] d w-\int_{\hat{w}}[1-F(w)] d w\right]+2 \frac{\alpha_{o}}{r} \int_{w^{* *}}^{\hat{w}} r \Omega^{\prime}(w)[1-F(w)] d w$.

Now, suppose $w^{* *} \geq \hat{w}$. Then the LHS becomes nonnegative. The last term in the RHS is negative. From the definition of $\phi_{i}\left(w_{1}\right), r \Omega\left(w_{1}\right)=r T\left(w_{1}, \phi_{i}\left(w_{1}\right)\right)=w_{1}+\phi_{i}\left(w_{1}\right)$. Thus, $\phi_{i}^{\prime}\left(w_{1}\right)=r \Omega^{\prime}\left(w_{1}\right)-$ 1 . But since we have proved that $\phi_{i}^{\prime}\left(w_{1}\right) \leq 0$ above $\hat{w}$, we have that $r \Omega^{\prime}\left(w_{1}\right) \leq 1$. Therefore, the first term in the RHS must also be negative, which delivers a contradiction and leads to $w^{* *}<\hat{w}$. Steps 1 and 2 establish that $w^{* *} \in\left(\hat{w}_{T}, \hat{w}\right)$.

Step 3: We next prove $w^{*} \in\left(\hat{w}, \hat{w}_{S}\right)$. Combining equation (32) evaluated at $\hat{w}$ with the fact that $r \Omega(\hat{w})=2 \hat{w}$, we have

$$
\hat{w}=b+\frac{\alpha_{i}}{r} \int_{\hat{w}}[1-F(w)] d w+\frac{\alpha_{o}}{r} \int_{\hat{w}} r \Omega^{\prime}(w)[1-F(w)] d w .
$$

Subtracting this equation from equation (33), we get

$$
w^{*}-\hat{w}=\frac{\alpha_{i}}{r} \int_{w^{*}}^{\hat{w}}[1-F(w)] d w+\frac{\alpha_{o}}{r}\left[\int_{w^{*}}[1-F(w)] d w-\int_{\hat{w}} r \Omega^{\prime}(w)[1-F(w)] d w\right] .
$$


Suppose $w^{*} \leq \hat{w}$, then the LHS becomes non-positive, but the RHS is strictly positive since $r \Omega^{\prime}(w) \leq 1$, a contradiction. Thus, $w^{*}>\hat{w}$.

Step 4: Finally we show that $w^{*}<\hat{w}_{S}$. Rewrite the equation for $\hat{w}_{S}$ as

$$
\hat{w}_{S}=b+\kappa+\frac{\alpha_{1}}{r} \int_{\hat{w}_{S}-\kappa}(1-F(w)) d w+\frac{\alpha_{2}}{r} \int_{\hat{w}_{S}}(1-F(w)) d w .
$$

Subtracting equation (33) from the equation defining $\hat{w}_{S}$, we get

$$
\hat{w}_{S}-w^{*}=\kappa+\frac{\alpha_{i}}{r} \int_{\hat{w}_{S}-\kappa}^{w^{*}}[1-F(w)] d w+\frac{\alpha_{o}}{r} \int_{\hat{w}_{S}}^{w^{*}}[1-F(w)] d w .
$$

Suppose $w^{*} \geq \hat{w}_{S}$, then the LHS is non-positive. However, since $\kappa>0$, the RHS is strictly positive. Thus, $w^{*}<\hat{w}_{S}$. Therefore, $w^{*} \in\left(\hat{w}, \hat{w}_{S}\right)$, and the proof is complete.

\section{B Multiple Locations Case: Value Functions}

Below, we report value functions for the economy with multiple locations and exogenous separations that we simulate in Section 5.2. The value of a couple of employed spouses who currently live together is

$$
r T\left(w_{1}, w_{2}\right)=w_{1}+w_{2}-\delta\left[T\left(w_{1}, w_{2}\right)-\Omega\left(w_{1}\right)\right]+\delta\left[T\left(w_{1}, w_{2}\right)-\Omega\left(w_{2}\right)\right],
$$

and the value of a couple whose members are employed but currently live in different locations is

$$
r S\left(w_{1}, w_{2}\right)=w_{1}+w_{2}-\kappa-\delta\left[S\left(w_{1}, w_{2}\right)-\Omega\left(w_{1}\right)\right]+\delta\left[S\left(w_{1}, w_{2}\right)-\Omega\left(w_{2}\right)\right] .
$$

We now turn to the worker-searcher couple. First, the unemployed spouse receives offers at rate $(1-\theta) \psi$ from the current location, in which case the couple faces the same options as in the one-location problem. Second, the same spouse receives outside offers at rate $\theta \psi$, in which case (i) the unemployed spouse can choose to accept the offer, the employed spouse would keep his job, and the couple could live separately, (ii) the household can accept the offer, and the currently employed spouse would quit his job, or (iii) the offer could be rejected. The value for a worker-searcher couple is therefore

$$
\begin{aligned}
r \Omega\left(w_{1}\right) & =w_{1}+b+(1-\theta) \psi \int \max \left\{T\left(w_{1}, w_{2}\right)-\Omega\left(w_{1}\right), \Omega\left(w_{2}\right)-\Omega\left(w_{1}\right), 0\right\} d F\left(w_{2}\right) \\
& +\theta \psi \int \max \left\{S\left(w_{1}, w_{2}\right)-\Omega\left(w_{1}\right), \Omega\left(w_{2}\right)-\Omega\left(w_{1}\right), 0\right\} d F\left(w_{2}\right)-\delta\left[\Omega\left(w_{1}\right)-U\right],
\end{aligned}
$$

and the value for an unemployed couple is

$$
r U=2 b+2 \psi \int \max \{\Omega(w)-U, 0\} d F(w) .
$$




\section{References}

[1] Acemoglu, Daron, and Robert Shimer (1999), "Efficient Unemployment Insurance," Journal of Political Economy, 107(5), 893-928.

[2] Aiyagari, Rao S., Jeremy Greenwood, and Nezih Guner (2000), "On the State of Union," Journal of Political Economy, 108(2), 213-44.

[3] Albrecht, Anderson, and Susan Vroman (2009), "Search by Committee," mimeo, Georgetown University.

[4] Blundell, Richard, Pierre-Andre Chiappori, Thierry Magnac, and Costas Meghir (2007), "Collective Labour Supply: Heterogeneity and Non-participation, Review of Economic Studies, vol. $74(2), 417-445$

[5] Browning, Martin, Thomas F. Crossley, and Eric Smith (2003), "Asset Accumulation and Short Term Employment," mimeo.

[6] Burdett, Kenneth (1978), "A Theory of Employee Job Search and Quit Rates," American Economic Review, 68(1), 212-220.

[7] Burdett, Kenneth and Dale Mortensen (1977), "Labor Supply Under Uncertainty," in Research in Labor Economics, Vol. 2, ed. R. G. Ehrenberg, 109-158, New York: JAI Press.

[8] Chiappori, Pierre-Andre (1992), "Collective Labor Supply and Welfare," Journal of Political Economy, 100(3), 437-67.

[9] Costa, Dora L., and Matthew E. Kahn (2000), "Power Couples: Changes in the Locational Choice of the College Educated, 1940-1990," Quarterly Journal of Economics, Vol 115, pp. $1287-1315$.

[10] Costain, James S. (1999), "Unemployment Insurance with Endogenous Search Intensity and Precautionary Saving," mimeo.

[11] Cubeddu, Luis, and Jose-Victor Rios-Rull (2003), "Families as Shocks, Journal of the European Economic Association, 1(2-3), 671-682.

[12] Danforth, John P. (1979), "On the Role of Consumption and Decreasing Absolute Risk Aversion in the Theory of Job Search, in Studies in the Economics of Search, ed. S. A. Lippman, and J. J. McCall, vol. 123 of Contributions to Economic Analysis, chap. 6, 109-131. Amsterdam: North-Holland.

[13] Dey, Matthew, and Christopher Flinn (2008), "Household Search and Health Insurance Coverage," Journal of Econometrics, 145(1-2), 43-64. 
[14] Garcia-Perez, J. Ignacio, and Silvio Rendon (2004), "Family Job Search and Consumption: The Added Worker Effect Revisited," mimeo.

[15] Gemici, Ahu (2008), "Family Migration and Labor Market Outcomes," mimeo New York University.

[16] Guner, Nezih, Remzi Kaygusuz, and Gustavo Ventura (2009), "Taxation, Aggregates and the Household," mimeo.

[17] Heathcote, Jonathan, Kjetil Storesletten, Giovanni L. Violante (2008), "The Macroeconomic Implications of Rising Wage Inequality in the U.S," Working Paper No. 14052, National Bureau of Economic Research.

[18] Hornstein, Andreas, Per Krusell, and Giovanni L. Violante (2007), "Frictional Wage Dispersion in Search Models: A Quantitative Assessment," mimeo.

[19] Krusell, Per, Toshi Mukoyama, and Aysegul Sahin (2007), "Labor Market Matching with Precautionary Saving and Aggregate Fluctuations, mimeo, Princeton University.

[20] Lentz, Rasmus (2009), "Optimal Unemployment Insurance in an Estimated Job Search Model with Savings," Review of Economic Dynamics, 12(1), 37-57.

[21] Lentz, Rasmus, and Torben Tranaes (2005), "Job Search and Savings: Wealth Effects and Duration Dependence," Journal of Labor Economics, 23(3), 467-489.

[22] Lise, Jeremy (2006), "On-the-Job Search and Precautionary Savings: Theory and Empirics of Earnings and Wealth Inequality," mimeo, University College London.

[23] Lise, Jeremy, and Shannon Seitz (2007), "Consumption Inequality and Intra-Household Allocations," mimeo.

[24] McCall, John J. (1970), "Economics of Information and Job Search," Quarterly Journal of Economics, 84(1), 113-126.

[25] Mincer, Jacob (1978), "Family Migration Decisions," Journal of Political Economy, 86(5), 749773.

[26] Mortensen, Dale T. (1970), "A Theory of Wage and Employment Dynamics," in Microeconomic Foundations of Employment and Inflation Theory, ed. E. S. Phelps et. al., New York: W.W. Norton.

[27] Pissarides, Christopher A. (2004), "Consumption and Savings with Unemployment Risk: Implications for Optimal Employment Contracts, IZA Discussion Paper 1183, Institute for the Study of Labor 
[28] Pratt, John, W. (1964), "Risk Aversion in the Small and in the Large," Econometrica, 32(1/2), 122-136.

[29] Raley, Sara B., Marybeth J. Mattingly, and Suzanne M. Bianchi (2006), "How Dual Are DualIncome Couples? Documenting Change from 1970 to 2001," Journal of Marriage and Family, $68(1), 11-28$.

[30] Rendon, Silvio (2006), "Job Search and Asset Accumulation Under Borrowing Constraints," International Economic Review, 47(1), 233-263.

[31] Rogerson, Richard, Robert Shimer and Randall Wright (2005), "Search Theoretic Models of the Labor Market: A Survey," Journal of Economic Literature, 43(4), 959-988.

[32] Rudanko, Leena (2008), "Aggregate and Idiosyncratic Risk in a Frictional Labor Market," mimeo, Boston University.

[33] Shimer, Robert, and Ivan Werning (2008), "Liquidity and Insurance for the Unemployed," mimeo, University of Chicago.

[34] Visschers, Ludo (2006), "A Note on Search and Assortative Matching in Wealth," mimeo. 